\title{
New whaitsioids (Therapsida: Therocephalia) from the Teekloof Formation of South Africa and therocephalian diversity during the end-Guadalupian extinction
}

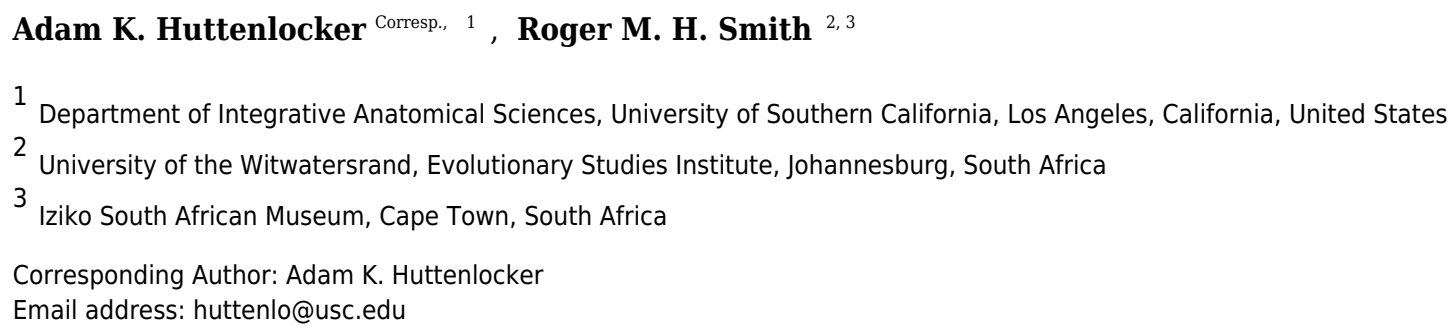

Two new species of therocephalian therapsids are described from the upper Permian Teekloof Formation of the Karoo Basin, South Africa. They include two specimens of a whaitsiid, Microwhaitsia mendrezi gen. et sp. nov., and a single, small whaitsioid Ophidostoma tatarinovi gen. et sp. nov., which preserves a combination of primitive and apomorphic features. A phylogenetic analysis of 56 therapsid taxa and 136 craniodental and postcranial characters places the new taxa within the monophyletic sister group of baurioids-Whaitsioidea - with Microwhaitsia as a basal whaitsiid and Ophidostoma as an aberrant whaitsioid just outside the hofmeyriid+whaitsiid subclade. The new records support that whaitsioids were diverse during the early-late Permian (Wuchiapingian) and that the dichotomy between whaitsiid-line and baurioid-line eutherocephalians was established early on. The oldest Gondwanan whaitsiid Microwhaitsia and additional records from the lower strata of the Teekloof Formation suggest that whaitsioids had diversified by the early Wuchiapingian and no later than Pristerognathus Assemblage Zone times. Prior extinction estimates based on species counts are reflected in an analysis of origination/extinction rates, which imply increasing faunal turnover from Guadalupian to Lopingian (late Permian) times. The new records support a growing body of evidence that some key Lopingian synapsid clades originated near or prior to the Guadalupian-Lopingian boundary ca. 260-259 million years ago, but only radiated following the end-Guadalupian extinction of dinocephalians and basal therocephalian predators (long-fuse model). Ongoing collecting in older portions of the Teekloof Formation (e.g., Pristerognathus Assemblage Zone) will shed further light on early eutherocephalians during this murky but critical time in their evolutionary diversification. 
1 New whaitsioids (Therapsida: Therocephalia) from the Teekloof Formation of

2

3

4

5

6

7

19

\section{1}

South Africa and therocephalian diversity during the end-Guadalupian extinction

4

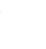

\section{ADAM K. HUTTENLOCKER ${ }^{1, *}$ and ROGER M. H. SMITH ${ }^{2,3}$}

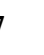

$8 \quad{ }^{1}$ Department of Integrative Anatomical Sciences, University of Southern California, Los

Angeles, California, U.S.A.;

${ }^{2}$ Evolutionary Studies Institute, University of the Witwatersrand, Johannesburg, South Africa;

${ }^{3}$ Iziko South African Museum, Cape Town, South Africa

12

13

4

*Corresponding author: ahuttenlocker@gmail.com

17

8 RH: HUTTENLOCKER \& SMITH-TEEKLOOF WHAITSIOIDS

20

22

23

24


25 ABSTRACT - Two new species of therocephalian therapsids are described from the upper

26 Permian Teekloof Formation of the Karoo Basin, South Africa. They include two specimens of a

27 whaitsiid, Microwhaitsia mendrezi gen. et sp. nov., and a single, small whaitsioid Ophidostoma

28 tatarinovi gen. et sp. nov., which preserves a combination of primitive and apomorphic features.

29 A phylogenetic analysis of 56 therapsid taxa and 136 craniodental and postcranial characters

30 places the new taxa within the monophyletic sister-group of baurioids - Whaitsioidea — with

31 Microwhaitsia as a basal whaitsiid and Ophidostoma as an aberrant whaitsioid just outside the

32 hofmeyriid+whaitsiid subclade. The new records support that whaitsioids were diverse during

33 the early-late Permian (Wuchiapingian) and that the dichotomy between whaitsiid-line and

34 baurioid-line eutherocephalians was established early on. The oldest Gondwanan whaitsiid

35 Microwhaitsia and additional records from the lower strata of the Teekloof Formation suggest

36 that whaitsioids had diversified by the early Wuchiapingian and no later than Pristerognathus

37 Assemblage Zone times. Prior extinction estimates based on species counts are reflected in an

38 analysis of origination/extinction rates, which imply increasing faunal turnover from

39 Guadalupian to Lopingian (late Permian) times. The new records support a growing body of

40 evidence that some key Lopingian synapsid clades originated near or prior to the Guadalupian-

41 Lopingian boundary ca. 260-259 million years ago, but only radiated following the end-

42 Guadalupian extinction of dinocephalians and basal therocephalian predators (long-fuse model).

43 Ongoing collecting in older portions of the Teekloof Formation (e.g., Pristerognathus

44 Assemblage Zone) will shed further light on early eutherocephalians during this murky but

45 critical time in their evolutionary diversification. 
Therocephalians were a major clade of non-mammalian therapsids whose fossils are best represented in rocks of the middle to late Permian (ca. 272-251.9 million years ago), with a few

51 lineages that survived into the subsequent Triassic Period (Abdala et al., 2008; Huttenlocker et al., 2011). They attained remarkable ecological diversity with wide-ranging body sizes and myriad dental (and, thus, dietary) specializations and other modifications of their feeding apparatus (Kemp, 1972a,b; Huttenlocker, 2014; Huttenlocker and Abdala, 2015; Huttenlocker et al., 2015). Moreover, they are the sister-group to cynodonts - the therapsid group that includes mammals - making them exceptionally important in our understanding of the origins of mammal-like behavior and physiology (Hopson and Barghusen, 1986; Hopson, 1991; van den Heever, 1994; Huttenlocker, 2009). Thus, there has been increasing interest in therocephalian paleobiology in recent years to clarify their evolutionary relationships (Huttenlocker, 2009; Huttenlocker et al., 2011; Kemp, 2012) and to understand their fluctuating diversity patterns within the context of the global biodiversity crises that disrupted terrestrial ecosystems of the late Paleozoic — the end-Guadalupian and Permo-Triassic mass extinctions (Huttenlocker et al., 2011; Huttenlocker, 2014).

Despite improvements in our understanding of therocephalian evolution, very little is known about the transition between the middle-to-late Permian, a critical period in the ecological expansion of therocephalians. Early therocephalian fossil localities are globally widespread-

67 particularly in present-day southern Africa and Russia-but their fossils are best known from the 68 middle Permian terrestrial vertebrate assemblages of the Karoo Basin, South Africa (Abdala et

69 al., 2008; Smith et al., 2012). Basal therocephalians of South Africa's middle Permian

70 (Guadalupian) Tapinocephalus and Pristerognathus assemblage zones (AZ) were large-bodied 
71 apex predators that fell into only a handful of genera and species (Abdala et al., 2008; Abdala et

72 al., 2014). By contrast, the later eutherocephalians that derived from this stock became highly

73 diverse with up to 70 genera (Abdala et al., 2008; Huttenlocker, 2013), and abruptly replaced the

74 earlier, archaic groups in the Karoo Basin by Tropidostoma AZ times. These eutherocephalians,

75 along with the gorgonopsians, remained among the most abundant terrestrial predators in early-

76 late Permian terrestrial assemblages in southern Africa (Smith \& Botha-Brink, 2011; Smith et al.,

77 2012). Moreover, a major dichotomy between baurioid-line and whaitsiid-line eutherocephalians

78 may have already taken place prior to the early-late Permian Tropidostoma AZ, as some museum

79 records of baurioid-line 'ictidosuchids' and whaitsiid-line hofmeyriids were collected from

80 Pristerognathus AZ-equivalent rocks of the lower Teekloof Formation (reviewed in

81 Huttenlocker, 2013 and this study).

82 Among Permian eutherocephalians, whaitsiids have received much taxonomic interest

83 primarily due to the unconventional hypothesis that they may share a relationship with

84 Cynodontia, thus positioning cynodonts within Therocephalia rather than as a close sister-group

85 (Kemp, 1972a; Abdala, 2007; Botha et al., 2007). Although this view has fallen out of favor (van

86 den Heever, 1994; Kemp, 2012; Abdala et al., 2014), little remains known about the diversity of

87 whaitsiid-line therocephalians or the detailed anatomy of their hypothetical common ancestor.

88 The taxonomic history of whaitsioids is complex. Tatarinov (1974) was the first author to

89 include his 'Annatherapsididae' (= Akidnognathidae), 'Moschowhaitsiidae,' and Whaitsiidae

90 within the more inclusive clade 'Whaitsioidea.' However, Mendrez (1974a) separated from

91 Whaitsiidae the akidnognathids and other forms that she did not see fit in either of the two

92 groups, such as the hofmeyriids Hofmeyria and Mirotenthes - previously regarded as whaitsiids

93 or "forerunners" of whaitsiids by Watson and Romer (1956:70) and other authors (e.g., Attridge, 
94 1956; Brink, 1956). Early cladistic investigations of therapsids also doubted the whaitsiid

95 affinities of akidnognathids and some hofmeyriids (Hopson and Barghusen, 1986; Abdala,

96 2007), although more recent revisions of therocephalian systematics and phylogeny have

97 supported the traditional view that hofmeyriids likely do share a relationship with whaitsiids

98 (Huttenlocker, 2009; Huttenlocker et al., 2011). Consequently, two major clades of post-

99 akidnognathid eutherocephalians are currently recognized: (1) Baurioidea and (2) a clade of

100 whaitsiids and hofmeyriids to which the term 'whaitsioids' has recently been repurposed

101 (Huttenlocker et al., 2015; Huttenlocker and Sidor, 2016; Maisch, 2017) though it has not been

102 formally defined until now.

103 Present Study - Here, we describe two new therocephalians from the western Karoo

104 Basin that shed light on the poorly known non-mammalian therapsid subclade Whaitsioidea.

105 These whaitsioid records were reported in prior studies (Sidor et al., 2013; Huttenlocker, 2014;

106 Huttenlocker et al., 2015; Huttenlocker and Sidor, 2016), but their anatomy is described and

107 illustrated here for the first time. The specimens were discovered in 1996 and 2011 on two

108 different farms near the border of the Northern and Western Cape provinces, respectively, both

109 from outcrops of the upper Permian Teekloof Formation (Fig. 1). Teekloof-equivalent rocks of

110 the Middleton and lower Balfour formations to the east of the study area have yielded

111 radiometric dates that suggest a relatively continuous sequence of middle to upper Permian rocks

112 in this part of the basin (Rubidge et al., 2013). The combination of constraints on their early-late

113 Permian ages (Wuchiapingian) coupled with their phylogenetic position near the whaitsiid stem

114 makes these new records an important datum for understanding the post-Guadalupian radiation

115 of eutherocephalians and of early non-mammalian therapsid faunas more generally. 
119 The Beaufort Group is the most extensively exposed stratigraphic unit of the Karoo

120 foreland basin sequence and consequently the most tetrapod fossils have been recovered from

121 this interval. In the southwestern sub-basin, Beaufort Group sedimentation was initiated by

122 source area tectonism and resulted in the deposition of an approximately 2,700 $\mathrm{m}$ thick

123 succession of fluvial channel sandstones and overbank mudrocks (Abrahamskraal and Teekloof

124 formations; Fig. 1) containing rich fossil tetrapod assemblages (i.e., Eodicynodon,

125 Tapinocephalus, Pristerognathus, Tropidostoma, Cistecephalus, and Daptocephalus AZs of Fig.

126 1). Sandstone-rich fining-upward packages from 50 to $300 \mathrm{~m}$ thick, described as megacycles,

127 occur within the succession. These packages are thought to be related to northeasterly,

128 northwesterly, and east-southeasterly directed fluvial transport systems and subsidence-

129 controlled shifts in the loci of channelization on the alluvial plain (Cole, 1992). The presence of

130 calc-alkaline volcaniclastic detritus and cherts of tuffaceous origin suggests that the provenance

131 rocks in the southwest may have included an active andesitic volcanic chain located on the

132 eastern side of the Andean Cordillera in South America and West Antarctica. Rubidge et al.

133 (2013) dated a series of these tuffs confirming that the Guadalupian-Lopingian boundary occurs

134 close to the top of the Abrahamskraal Formation (Fig.1).

135 The overlying Wuchiapingian-aged Teekloof Formation in which the new

136 therocephalians were found was deposited by overbank flooding from meandering rivers of

137 variable sinuosity draining an extensive alluvial plain sloping gently towards the northeast in the

138 direction of the receding Ecca shoreline (Turner, 1978). Deposition occurred under semi-arid

139 climatic conditions as evidenced by the presence of desiccation cracks, playa lake evaporite 
140 deposits with desert-rose gypsum aggregates and pedogenic carbonate nodules and lenses

141 (Smith, 1990, 1993). The irregular accretion topography and preferential preservation of upper

142 flow regime plane beds and lower flow regime ripple cross-lamination within channel sand

143 bodies (Smith, 1987) indicates a flood-dominated discharge regime and seasonal inundation of

144 the floodplains resulting in rapid bone burial (Smith, 1993).

145 The two new therocephalian skulls (SAM-PK-K10984, SAM-PK-K10990) collected

146 from Badshoek (De Hoop 17) are from the same mudrock interval in the middle of the

147 Hoedemaker Member (Tropidostoma AZ, +/- 257 Mya). They were found as isolated skulls and

148 were encrusted with a 2 mm-thick layer of pedogenically-precipitated micrite. Associated

149 dicynodont taxa collected in the same strata include Tropidostoma, Emydops, Pristerodon and

150 Diictodon, as well as a small gorgonopsian (see Table 1).

151 The Good Luck (Matjiesfontein 412) specimens (SAM-PK-K8516, SAM-PK-K8631)

152 were collected from massive gray siltstone beds in the upper Oukloof Member (upper

153 Cistecephalus AZ, +/- 255 Mya) along with several skulls and partial skeletons of Cistecephalus,

154 Oudenodon, Diictodon, Procynosuchus and Pareiasaurus (see Table 1).

155

156

157

158

159

160

161

162

\section{MATERIAL AND METHODS}

The electronic version of this article in Portable Document Format (PDF) will represent a published work according to the International Commission on Zoological Nomenclature (ICZN), and hence the new names contained in the electronic version are effectively published under that Code from the electronic edition alone. This published work and the nomenclatural acts it contains have been registered in ZooBank, the online registration system for the ICZN. The 
163 ZooBank LSIDs (Life Science Identifiers) can be resolved and the associated information viewed

164 through any standard web browser by appending the LSID to the prefix http://zoobank.org/. The

165 LSID for this publication is: urn:lsid:zoobank.org:pub:4D798F6D-74BC-4FE8-BA46-

166 79DAA314FE09. The online version of this work is archived and available from the following

167 digital repositories: PeerJ, PubMed Central and CLOCKSS.

168

169

SYSTEMATIC PALEONTOLOGY

170

171

THERAPSIDA Broom, 1905

172

THEROCEPHALIA Broom, 1903

173

EUTHEROCEPHALIA Hopson and Barghusen, 1986

174

WHAITSIOIDEA Tatarinov, 1974

175

176

Composition-Theriognathus microps Owen, 1876; Ictidostoma hemburyi (Broom,

1911); Hofmeyria atavus Broom, 1935; Ictidochampsa platyceps Broom, 1948; Mirotenthes

178 digitipes Attridge, 1956; Moschowhaitsia vjuschkovi Tatarinov, 1963; Viatkosuchus sumini

179 Tatarinov, 1995; Microwhaitsia mendrezi gen. et sp. nov.; Ophidostoma tatarinovi gen. et sp.

180 nov.

181 Definition-The most inclusive clade that contains Theriognathus microps and

182 Ictidostoma hemburyi, but not Ictidosuchus primaevus and Bauria cynops [stem-based].

183 Revised diagnosis - Small- to large-bodied therocephalians having a wide suborbital bar

184 forming well-frontated orbits; ventromedially infolded maxilla with medially positioned tooth

185 row so that much of the maxillary facial lamina is visible in ventral view; anterior border of orbit 
186 is located on anterior half of skull (conv. in cynodonts, Lycosuchus, some akidnognathids, and

187 derived bauriamorphs); epipterygoid anteroposteriorly expanded; epipterygoid processus

188 ascendens anterior edge orientation in lateral view is strongly anterodorsal (rather than

189 posterodorsal or vertical) producing an anvil-shape; dentary tall and boomerang-shaped; and

190 dentary ramus lateral groove weak (Ophidostoma) or absent (all others).

191

192

193

194

195

196
WHAITSIIDAE Haughton, 1918

Composition-Theriognathus microps Owen, 1876; Ictidochampsa platyceps Broom, 1948; Moschowhaitsia vjuschkovi Tatarinov, 1963; Viatkosuchus sumini Tatarinov, 1995;

Microwhaitsia mendrezi gen. et sp. nov.

Definition - The most inclusive clade that contains Theriognathus microps and

Viatkosuchus sumini, but not Ictidostoma hemburyi and Hofmeyria atavus [stem-based].

Revised diagnosis-Medium-to-large eutherocephalians with median frontonasal crest (also in Chthonosaurus and akidnognathids); suborbital vacuities reduced in size or absent; prefrontal and postorbital nearly contact, limiting contribution of frontal to dorsal border of orbit; epipterygoid extremely expanded anteroposteriorly (more so than hofmeyriids); epipterygoid posterior apophysis forms specialized "trigeminal notch"; pterygoid boss teeth usually absent (though present in Viatkosuchus).

MICROWHAITSIA MENDREZI gen. et sp. nov.

(Figs. 2-6) 
210 epithet honors Christiane Mendrez-Carroll for her substantial contributions to the morphology

211 and systematics of therocephalians.

212 Holotype-Iziko South African Museum (SAM) PK-K10990, partial skull with dentaries

213 preserved in occlusion, missing most of the braincase, occiput, and postdentary bones (Figs. 2$2144)$.

Referred specimen-SAM-PK-K10984, weathered snout preserving most of the left antorbital region, palate, and maxillary canine and postcanine alveoli (Figs. 5-6).

Locality and horizon-Both specimens were collected by RMHS in 2011 from Badshoek farm (De Hoop 117) near Beaufort West District, Western Cape Province, Republic of South Africa; upper Tropidostoma Assemblage Zone (Wuchiapingian stage), upper Permian Teekloof Formation (Hoedemaker member). Detailed locality information is available at Iziko South African Museum, Cape Town.

Diagnosis-Small-to-medium sized therocephalian with broad, robust skull; nasals strongly waisted at mid-length in dorsal view; thickened, pachyostotic frontal bone; thickened suborbital bar (nearly as deep as the orbit's dorsoventral height); upper dental formula I5:pC1:C1:PC5; lower dental formula i4:c1:pc5.

\section{General Description}

In general, the two specimens of Microwhaitsia show a robust snout, cheek, and dentition, and are similar to each other in overall size (estimated skull lengths $\sim 180 \mathrm{~mm}$ ). The skull roofs are strongly sutured and craniofacial bones fairly thick for their small size. The holotypic skull--SAM-PK-K10990--is nearly complete with dentition and both lower dentaries 
232 intact in occlusion, but it is missing much of the occiput and intertemporal region, as well as the

233 postdentary bones. The referred specimen--SAM-PK-K10984--is a weathered snout and left

234 antorbital region, missing the premaxilla, and most of the right side of the skull. The dentition is

235 also missing from the referred specimen. In both specimens, cranial sutures are easily

236 distinguished and tend to be noticeably sinuous and interdigitating, with few straight sutures

237 except along the midline. The braincase and occiput are not preserved in either specimen.

\section{Skull Roof}

The premaxilla is a three-part element consisting of maxillary, vomerine, and dorsal

240 (internarial) processes. The maxillary portion bears a short interdigitating suture with the maxilla

241 that borders a small nervous foramen and, more dorsally, the septomaxillary foramen. Dorsally,

242 the internarial process forms the medial septum of the naris and is fairly short, not reaching

243 posteriorly beyond the level of the septomaxilla. The holotype preserves five premaxillary

244 (incisor) alveoli. The septomaxilla is a rather large, solid element, but it is not well exposed

245 outside of the naris. There is a modest dorsal process within the naris. The ventral footplate

246 shares little overlap with the premaxilla externally, and the posterior facial process is fairly short

247 dorsal and medial to the septomaxillary foramen.

248 The maxilla is the dominant element of the rostrum, having an exceptionally high facial

249 lamina. The facial lamina is so high and broad and that very little of the nasal can be seen in

250 lateral view (Figs. 2, 3). It is highest anteriorly and, when viewed laterally, rapidly tapers just

251 behind the anterior border of the orbit ventral to the jugal. The lateral surface of the rostrum is

252 coarsely pitted by many nervous foramina in front of the antorbital depression. In ventral

253 (palatal) view, the maxilla borders a fossa for the lower canine and expands behind this area

254 forming a crista choanalis (Fig. 4). The crista is sufficiently expanded that it just contacts the 
255 vomer dorsally (Fig. 4B), separating the anterior (canine fossa) and posterior portions of the

256 choana. However, there is no true maxillovomerine bridge as the connection is not sutural

257 (unlike Theriognathus and Moschowhaitsia where the two elements are sutured). Attachment

258 sites for maxilloturbinates on the medial side of the facial lamina could not be discerned.

259 The nasal is relatively long and narrow despite the broad, round profile of the snout. This

260 is in part influenced by the large size of the maxilla facial laminae, which give the nasals a

261 waisted appearance along their mid-length in dorsal view.

262 The lacrimal is a short, square element on the anterolateral margin of the orbit. It is much

263 abbreviated due to the tall, broad facial lamina of the maxilla. Dorsally, it is bordered by the

264 anterior tongue of the prefrontal, which contacts the maxilla and, thus, bars the lacrimal from

265 contacting the nasal, as in most other therocephalians (except lycideopids). Just anterior to the

266 orbit, near the contacts with the jugal and maxilla, there is a marked antorbital fossa which bears

267 the lacrimal foramina (as in the therocephalian Hofmeyria and, convergently, burnetiamorph

268 therapsids). One large foramen occupies a position on the anterior rim of the orbit, whereas the

269 other smaller foramen is situated more ventrolaterally near the jugal-maxilla suture. The details

270 of the nasolacrimal canal and its communication with the internal (medial) face of the maxilla

271 could not be determined at present.

272 The prefrontal forms the anteromedial border of the orbit. It contacts the lacrimal

273 ventrolaterally and the maxilla and nasal anteriorly. The posterior process does not contact the

274 postorbital over the orbit, so that a small portion of the frontal contributes to the margin of the

275 orbit. The prefrontal and postorbital nearly meet inside the orbit as in Theriognathus (Fig. 2C).

276 The frontal is very thick and pachyostotic ( $\sim 13 \mathrm{~mm}$ thick at midorbit level). In dorsal

277 view, it is roughly diamond-shaped with stout lateral processes narrowly contacting the orbital 
278 margin. The element's anterior extent just reaches the level of the anterior margin of the orbit

279 where it strongly interdigitates with the nasal. There is a prominent median frontonasal crest on

280 the midline as in other whaitsiids. The midline suture is comparatively straight except at the

281 midorbit level where it becomes noticeably jagged.

282 The postorbital bounds the posteromedial margin of the orbit. The postorbital bar is

283 robust and strongly sutures to the jugal. Most of the bar is formed by the broad postorbital

284 process of the jugal. As in Theriognathus and other whaitsiids, the jugal is a substantial element,

285 promoting the robust appearance of the skull despite its small size. However, the total depth of

286 the suborbital bar is more so than in other whaitsiid genera, being $40-50 \%$ the height of the skull

287 (nearly as tall as the orbit itself) (Figs. 2C, 3C). By contrast, hofmeyriids have comparatively

288 thin suborbital bars (e.g., Hofmeyria, Mirotenthes).

289 Braincase and Occiput

Most of the braincase and occiput are missing from the specimens. However, the bisected 291 referred specimen clearly shows portions of the sphenethmoid preserved in place. The

292 sphenethmoid complex has been described in a few therocephalians, including Ictidosuchoides

293 (Crompton, 1955), Microgomphodon (Abdala et al., 2014), Tetracynodon (Sigurdsen et al., 294 2012), and Theriognathus (Kemp, 1972; Huttenlocker and Abdala, 2015). The anterodorsal

295 portion of the sphenethmoid complex, the orbitosphenoid, resides just dorsal and posterior to the 296 vomer, forming a broad but thin ascending lamina that would have made up the anteromedial 297 wall of the orbit. As in Tetracynodon, there is a broadly convex notch along its posterior margin 298 that may have accommodated the optic nerve (Sigurdsen et al., 2012: fig.2). Its dorsal most 299 extent nearly contacts the ventral surface of the frontal, but is separated by a small fissure.

300 Palate, Splanchnocranium, and Suspensorium 
302 process that widens anteriorly as in other therocephalians and is widest at its anterior contact

303 with the premaxilla. Although the crista choanalis just contacts the vomer anterodorsally,

304 creating the appearance of a strongly vaulted palate, there is no true maxillovomerine bridge.

305 There is a modest median crest that runs longitudinally along the vomer's ventral margin, and a

306 suture that separates the vomer into right and left halves spans the entire posterior region and

307 much of the length of the interchoanal process (as in basal therocephalians and some hofmeyriid 308 specimens).

309 The crista choanalis is short and smoothly rounded, rolling onto the palatine and

310 terminating just anterior to the suborbital vacuity. As in other whaitsiids, there are at least two

311 prominent ridges formed in this region: one that is confluent with the vomer-palatine suture

312 emarginating the choana and a second that is more laterally positioned and confluent with the

313 palatine-maxilla suture and alveolar margin (Figs. 5B, 6B). The maxilla-palatine foramen is

314 positioned somewhat posteriorly, just medial to the first and second postcanines. The

315 ectopterygoid is preserved on the left side of the skull in the referred specimen. It formed a

316 narrow strut bracing between the palatine, maxilla, and jugal along the anterolateral margin of

317 the suborbital vacuity. It is pierced ventrally by a small foramen. Little of the pterygoid could be

318 discerned in either specimen. Likewise, the epipterygoid and the suspensorium (including the

319 quadrate-quadratojugal complex) are not preserved in either specimen.

\section{Mandible}

321 Portions of the left and right lower jaws are preserved in the holotypic specimen,

322 including the left and right dentaries and splenials, right coronoid, right prearticular, and right

323 surangular. The dentary is a robust element with a thick mentum that was only loosely sutured at 
324 the symphysis. The overall shape is strongly bowed as in other whaitsioids. The lateral surface of

325 the ramus is smooth, bearing no dentary groove or trough. The anterior surface of the mentum is

326 pitted with fine vascular foramina. The coronoid process is very tall, terminating in the upper

327 half of the orbit, and its terminal margin is slightly rounded. On the medial surface of the

328 dentary, a long, flat splenial can be seen running anteriorly and meeting on the left and right

329 sides just behind the dentary symphysis. Just posterior and dorsal to the splenial on the right side,

330 a single coronoid and anterior portions of the prearticular are preserved, bounding the anterior

331 and lower parts of the mandibular fenestra. The anterior half of the surangular is preserved on the

332 medial surface of the dentary coronoid process and forms the upper border of the mandibular

333 fenestra. The majority of the postdentary region is not preserved.

334 Dentition

335 The dentition is best preserved in the holotypic specimen, although maxillary alveoli are

336 also present in the referred specimen. The holotype preserves five upper incisors, one upper

337 precanine, one upper canine (a second root of a previously functional canine is also preserved on

338 the left side of the skull immediately behind the newly functional canine), and five upper

339 postcanines. The dentary preserves four lower incisors, a single lower canine, and five lower

340 postcanines. As in most whaitsioids and early eutherocephalians in general, longitudinal fluting

341 of the enamel was likely present on the incisors based on the fifth left upper incisor, which is the

342 best preserved. However, most of the dentition is highly abraded, making the enamel texture

343 difficult to examine. In general, the incisor crowns are subcircular in cross-section and lack

344 serrations or mesio-distal carinae. The upper canine is fairly large, subcircular in cross-section,

345 and also lacks serrations or carinae. Following a short diastema, the postcanines are preserved as

346 simple, conical crowns that are subcircular in cross-section. These also lack any serrations or 
347 mesio-distal carinae. The surface enamel of the postcanines is too poorly preserved to discern

348 any postcanine fluting.

349

WHAITSIOIDEA incertae sedis

(Figs. 7-8)

353

Etymology-Tatarinov's 'snake mouth.' Ophido-(Greek, 'snake' or 'serpent'); stoma

355 (Greek, 'mouth'). Genus name refers to the wide gape permitted by the loose mandibular

356 symphysis and streptostylic jaw of whaitsioid therocephalians. Species epithet honors Leonid

357 Tatarinov for his contributions to whaitsioid systematics and therocephalian functional anatomy.

Holotype-SAM-PK-K8516, weathered skull and articulated mandible missing portions of palate and braincase (Figs. 7-8).

Locality and Horizon-The specimen was collected by RMHS in 1996 on 'Good Luck' farm (Matjiesfontein 412) near Fraserburg District, Northern Cape Province, Republic of South Africa; upper Cistecephalus Assemblage Zone (Wuchiapingian stage), upper Permian Teekloof Museum, Cape Town. occiput approximately equal to basal skull length); frontal length-to-width ratio approximately

367 1.0; pineal opening situated on raised boss; pterygoid boss teeth present; upper dental formula:

368 I?:C1:PC6. Plesiomorphic in the retention of longitudinal striae/fluting on upper postcanines

369 (primitive for eutherocephalians). 


\section{General Description}

The specimen consists of a small, poorly preserved skull and mandible (skull length from

373

374

375

376

377

378

379

380

381

382

occipital condyle to tip of snout $\sim 60-65 \mathrm{~mm}$ ), with the right side of the skull slightly crushed and the lower jaw laterally displaced. Its most recognizable features are the stout rostrum and the broad zygoma, producing a skull that is as wide as it is long.

The specimen was prepared using a pneumatic scribe so that most of the outer surface of the skull roof and mandible was exposed, and the ventral surface prepared to the palate. The skull was then scanned using high-resolution X-ray computed tomography (HRXCT) at the University of Utah Core Imaging Facility to reveal aspects of the palate, cranial sinuses, and braincase. It was scanned using an Inveon $\mu$-CT scanner with scanner settings: $100 \mathrm{kV}$ and 60 $\mu \mathrm{A}$ with a voxel size of $90 \mu \mathrm{m}$. Stacks were volumized and studied in OsiriX (Rosset et al., 2004). Unfortunately, the HRXCT data revealed that much of the palate and basicranium was 'blown-out' prior to fossilization, leaving only the skull roof, peripheral portions of the braincase and basicranium, and mandible.

The specimen has suffered from slight pre-burial distortion, including flaring of the right cheek and loss of the right zygoma, allowing ventrolateral displacement of the dentary ramus, although connection to the left dentary at the symphysis was maintained (Figs. 7D, 8D). The squamosal is also displaced slightly anteriorly within the temporal fossa on both sides. This distortion has led the authors to consider the possibility that the striking breadth of the skull relative to its short length was a result of postmortem crushing or other deformation. However, these proportions likely did not result from preservational artifact because large portions of the 
392 skull roof are preserved in articulation and some in situ cranial calvariae are clearly broad with

393 their widths being subequal to or slightly greater than their lengths (e.g., frontal).

\section{Skull Roof}

395 The maxilla is a very tall element with a broad facial lamina. The canine was deeply

396 rooted, although it is mostly weathered and missing the entire crown. As in other whaitsioids, the

397 facial lamina of the maxilla gently rolls onto the ventral (palatal) surface to meet the abbreviated

398 alveolar margin (Figs. 7B, 8B). There are six closely packed postcanines situated along the

399 alveolar margin on the right side of the skull. In palatal view, the choana can be seen to have

400 been short and the crista choanalis also fairly short and rounded (rather than sharp medially). The

401 medial surface of the facial lamina is smooth and shows no evidence for attachment of maxillary

402 turbinates as in most other therocephalians (Huttenlocker et al., 2011; Sigurdsen et al., 2012; but

403 see Hillenius, 1994). Internally, there is a large, cavern-like anterior maxillary sinus (sensu

404 Sigurdsen, 2006) as in other therocephalians that have been serially sectioned or CT scanned

405 (Sigurdsen et al., 2012). The sinus opens anteriorly onto the medial surface of the maxilla. A

406 posterior duct parallels the tooth row, leading into a smaller sinus (the posterior maxillary sinus;

407 sensu Sigurdsen, 2006) that opens posteriorly into a shallow fossa on the medial surface of the

408 maxilla just behind the tooth row.

409 The nasals are imperfectly preserved in SAM-PK-K8516, with most of the left side

410 weathered away and the right badly fractured. Surface features and nasoturbinal ridges could not

411 be discerned due to this damage. In life, the nasals would have been fairly short and broad as in

412 the other skull roof elements.

413 The lacrimal is a square element that forms part of the anterior wall of the orbit and

414 extends internally onto the palate. Two small nasolacrimal foramina located on the anterior 
415 margin of the orbit open into the nasolacrimal canal. The canal forms a narrow caliber duct that

416 opens onto the medial surface of the facial lamina of the maxilla near the maxilla-lacrimal suture.

417 The prefrontal is a tall and broad element that forms most of the anteromedial margin of

418 the orbit. It is fairly fractured on the right side of the skull and slightly weathered on the left so

419 that its precise suture contacts are difficult to determine. However, given its breadth and the high

420 facial lamina of the maxilla, it is likely that it contacted the maxilla anteriorly so that a

421 nasolacrimal contact was not permissible as in most therocephalians.

422 The frontal forms a broad diamond that is as wide as it is long, a rare feature in a

423 therocephalian. The interorbital breadth is therefore relatively wider than in other

424 therocephalians. The dorsal surface is flat and smooth so that there is no median frontonasal

425 crest. The frontal contributes strongly to the dorsomedial wall of the orbit, widely separating the

426 prefrontal and postorbital. This contrasts with the condition in other whaitsioids where the latter

427 elements contact in the upper wall of the orbit (hofmeyriids) or nearly contact along its dorsal

428 margin (whaitsiids).

429 The postorbital is a lunate element forming most of the posterior border of the orbit. Its

430 jugal process is long and robust, although its connection to the jugal is not preserved due to

431 damage to the zygoma on both sides of the skull. More posteriorly, the postorbital broadly

432 overlaps the parietal extending beyond the level of the pineal foramen.

433 The jugal is incompletely preserved, forming only a portion of the ventrolateral margin of

434 the orbit and missing the postorbital and zygomatic processes. Based on the preserved portions,

435 the suborbital bar was very slender as in Hofmeyria and Mirotenthes. The squamosal is

436 disarticulated on both sides of the skull, being displaced anteromedially into the temporal fossa.

437 It is tall and thin with a broadly concave anterior face that, when articulated, overlapped the 
438 supraoccipital, interparietal, and parietal. The sutural overlap with the parietal was extensive as

439 in the postorbital.

440 The parietal is a tall element forming the dorsolateral walls of the braincase, which are

441 vertical and parallel-sided as in other eutheriodonts. The parietal (sagittal) crest is short behind

442 the pineal foramen. Internally, the enclosure forming the pineal canal is deep and the external

443 opening large and situated on an elevated parietal boss. The interparietal could not be discerned

444 with certainty due to crushing in this region and anterior displacement of the supraoccipital.

\section{Braincase and Occiput}

$446 \quad$ Very little of the braincase and occiput are preserved in SAM-PK-K8516. The

447 sphenethmoid complex could not be observed in the prepared specimen or in the CT scans. Small

448 portions of the wedge-shaped supraoccipital are preserved on the left and right sides of the skull

449 in close association with the parietal. Ventral to this, a tiny portion of the right exoccipital is

450 preserved in contact with the basioccipital where the two would have bounded the foramen

451 magnum. There is a strong basicranial girder formed between the ventromedian keel of the

452 parabasisphenoid and the paired parasagittal processes of the pterygoid. The basal tubera are of

453 moderate size (approximately $25 \%$ the width of the skull). The prootics and opisthotics are too

454 poorly preserved to describe in detail.

455 Palate, Splanchnocranium, and Suspensorium

456 Much of the palate is unpreserved so that the relationships between the vomer, palatines

457 and ectopterygoids cannot be described in detail. The maxillae bear a modest crista choanalis

458 that border a fairly short choana. The crista is low and rounded, rather than sharp and distinct.

459 Although the vomer is not preserved, a maxillovomerine bridge was likely to have been absent

460 based on the lack of obvious medial (palatal) processes of the maxilla near the level of the canine 
461 or posterior to it. Portions of the pterygoid are preserved more posteriorly, showing well-

462 developed transverse flanges that formed the posterior border of the suborbital vacuity. The

463 flanges sweep medially and posteriorly where they formed paired parasagittal ridges bounding a

464 wide interpterygoid vacuity. Pterygoid boss teeth are present, with three small, longitudinally

465 arranged denticles present on the right and a large tooth preserved centrally on the left boss. The

466 quadrate processes and the dorsally adjoining epipterygoid are not preserved. A massive element

467 that rests within the quadrate recess of the squamosal on the left side of the skull is interpreted

468 tentatively as the quadrate-quadratojugal complex.

469 Mandible

470 The mandible is preserved on the left and right sides of the skull. The left mandible is

471 largely in place and held in occlusion, whereas the right is slightly ventrolaterally displaced and

472 disarticulated. The dentary is long and strongly bowed, with the distinctive boomerang-shape

473 that is common amongst whaitsioids. The coronoid process is broken on the left side, but is

474 preserved on the right where it can be seen as an extremely tall element. This tall process would

475 have terminated in the upper half of the temporal fenestra as in Hofmeyria and Mirotenthes. Its

476 terminal margin is somewhat rounded. Along the ramus, there is a very modest lateral dentary

477 groove (or trough), unlike in other whaitsioids that lack this feature entirely. Internally, there is a

478 large nervous canal that runs the length of the dentary, dorsal to the Meckelian groove, and feeds

479 the alveoli. Medially, portions of the prearticular are preserved in contact with the Meckelian

480 groove in the left side. The dentary, prearticular, and angular border a fairly large mandibular

481 fenestra as in other eutherocephalians. The angular bears a broad but thin reflected lamina with

482 radiating ridges and a dorsal notch. The surangular borders the reflected lamina dorsomedially.

483 The presence of an articular in the specimen could not be confirmed. 


\section{Dentition}

485 Due to damage to the premaxilla, the upper incisors are not preserved in the specimen.

486 The upper canines are large and deeply rooted, although their crowns have also weathered away

487 almost completely. Six postcanines are present in the right maxilla, although the roots of only

488 three are preserved on the left. The crowns are short, conical with circular cross-sections and

489 lacking carinae, and bear fine longitudinal striae on their external surface as in some basal

490 akidnognathids (i.e., Akidnognathus) and baurioids (i.e., Ictidosuchus). Just anterior to the

491 position of the second postcanine, a replacement tooth can be seen emerging from the maxilla on

492 the right side.

493 Most of the lower incisors are missing, although a single pair of incisors (presumably in

494 the fourth position) is preserved on both the left and right dentary, each pressed against the

495 mesial surfaces of the lower canines. Their surface texture is abraded such that the presence of

496 enamel striae (as in the postcanines) cannot be confirmed. The tooth row is very short with most

497 of the teeth (including the postcanines) restricted to the anterior third of the dentary. There are at

498 least four (and likely more) lower postcanines packed tightly together behind the lower canine.

499 The anteriormost postcanine in the right dentary preserves enamel striae.

RESULTS \& DISCUSSION

502

\section{Phylogenetic Position of New Whaitsioids}

504 Whereas early cladistic investigations regarded hofmeyriids as relatively basal

505 eutherocephalians (Hopson and Barghusen, 1986; Abdala, 2007), more recent studies have

506 supported that they are most closely related to whaitsiids, such as Theriognathus (Huttenlocker 
507 and Abdala, 2015). Prior to the present study, the holotypic specimens of Microwhaitsia and

508 Ophidostoma were incorporated into a preliminary phylogenetic analysis and were referenced

509 only by their voucher numbers (Huttenlocker, 2014; Huttenlocker et al., 2015; Huttenlocker and

510 Sidor, 2016). We assessed the phylogenetic positions of Microwhaitsia and Ophidostoma using a

511 matrix of 136 craniodental and postcranial characters from 56 therapsid taxa (including two

512 outgroups Biarmosuchus and Titanophoneus, plus 54 neotherapsid ingroup taxa) (see

513 Supplementary Appendices S1 and S2). The data were analyzed in PAUP*4.0b10 (Swofford,

514 1999) and MrBayes v. 3.2.6 (Ronquist et al., 2009). A heuristic search was performed in PAUP

515 using maximum parsimony with a random addition sequence with 100 replicates and the tree-

516 bisection-reconnection (TBR) branch-swapping algorithm. Characters were not ordered and all

517 given equal weight. Multistate characters were interpreted as uncertainty. The Bayesian analysis

518 was performed using the standard Mk model for morphological evolution (Lewis, 2001) with

519 variable character rates. We ran the analysis for one million generations (with the first $25 \%$

520 removed as burn-in) and sampled the posterior distribution every 100 generations.

521 Parsimony analysis recovered 1160 equally most parsimonious trees (MPTs) having a

522 length of 381 steps (consistency index $(\mathrm{CI})=0.438$; retention index $=0.789$; rescaled $\mathrm{CI}=$

523 0.346). The analysis found Hofmeyriidae, Whaitsiidae, and Baurioidea to represent

524 monophyletic clades nested within Eutherocephalia. The high number of MPTs differed only in

525 their volatile arrangements of basal scylacosaurid therocephalians, basal (ictidosuchid-grade)

526 baurioids, and Triassic bauriids. Though the major (deep) branches of eutherocephalians are

527 relatively stable, there were notable differences between parsimony and Bayesian-based

528 approaches. In particular, the interrelationships of basal therocephalians are poorly resolved in

529 the Bayesian topology, which fails to support the monophyly of Scylacosauridae. Moreover, the 
530 Bayesian topology yields a major eutherocephalian polytomy between Perplexisauridae,

531 Chthonosauridae, Akidnognathidae, and the Whaitsioidea+Baurioidea clade. It also recovers the

532 baurioid family Lycideopidae as the monophyletic sister-group to Bauriamorpha, while the

533 parsimony trees recover Lycideopidae as a paraphyletic assemblage that includes Bauriamorpha

534 as a subgroup. To account for these uncertainties, we present a conservative topology in Figure 9

535 that illustrates the conflicting parsimony and Bayesian arrangements as polytomies.

536 All of the MPTs retrieved a monophyletic Whaitsiidae composed of the Permian

537 eutherocephalians Ictidochampsa (Broom, 1948), Viatkosuchus (Tatarinov, 1995),

538 Moschowhaitsia (Tatarinov, 1963), and Theriognathus (Owen, 1876). Microwhaitsia is found to

539 be nested within whaitsiids as the sister-taxon to Viatkosuchus + (Moschowhaitsia +

540 Theriognathus). Among whaitsioids, characters shared between Microwhaitsia and other

541 whaitsiids include: median frontonasal crest present; suborbital bar robust, deepened; postorbital

542 bar moderately well built (extremely slender in hofmeyriids and baurioids); prefrontal and

543 postorbital nearly contact on dorsomedial wall of orbit; upper postcanines reduced to five or

544 fewer. Based on the character evidence, Viatkosuchus and Microwhaitsia would together

545 represent the geologically oldest occurrences of whaitsiids in Laurasia and Gondwana,

546 respectively (discussed further below).

547 Ophidostoma is found to be nested within Whaitsioidea, but the specimen does not

548 demonstrate clear features that unite it with any given whaitsioid subgroup. Based on gross

549 similarities to hofmeyriids, Huttenlocker et al. (2015) labeled Ophidostoma as 'Cistecephalus

550 AZ hofmeyriid' (Huttenlocker et al., 2015:fig. 6). However, the present analysis shows that

551 Ophidostoma falls outside the clade that includes the closest common ancestor of

552 Hofmeyriidae +Whaitsiidae, indicating that it is an aberrant whaitsioid and that its hofmeyriid- 
553 like gestalt represented plesiomorphies shared by all whaitsioids.

554 Whaitsioidea-Baurioidea dichotomy - The present phylogenetic hypothesis further

555 implies a major dichotomy between two non-akidnognathid eutherocephalian radiations during

556 the Permian: Whaitsioidea and Baurioidea. In general, the whaitsioids were characterized by

557 small and large-bodied species (skull lengths ranging $\sim 6-35 \mathrm{~cm}$ ) with a broad cranium having

558 greater area for the jaw adductor musculature, a robust, boomerang-shaped mandible, and a

559 tendency toward reduction of the postcanine teeth, whereas baurioids typically consisted of small

560 to mid-sized species (skull lengths ranging $\sim 5-20 \mathrm{~cm}$ ) with a low, slender rostrum and numerous

561 postcanines. A close relationship between whaitsioids and baurioids was originally demonstrated

562 by Huttenlocker (2009), who suggested that their common ancestry could be traced to no later

563 than the middle-to-late Permian transition during Pristerognathus AZ times.

$564 \quad$ Unlike Ivakhnenko's (2011) usage of 'Whaitsioidea' which included lycosuchids and

565 akidnognathids as subgroups - thus, making the name equivalent to Therocephalia —we define

566 Whaitsioidea explicitly as the most inclusive clade that contains Theriognathus microps and

567 Ictidostoma hemburyi, but not Ictidosuchus primaevus and Bauria cynops [stem-based]. As such,

568 the group includes representative hofmeyriid and whaitsiid taxa (e.g., Hofmeyria,

569 Theriognathus), but excludes akidnognathids and baurioids. Permian whaitsioids share a number

570 of craniodental synapomorphies that distinguish them from the latter two groups, including: a

571 wide suborbital bar forming well-frontated (i.e., forward-facing) orbits; ventromedially infolded

572 maxilla facial lamina with concave alveolar margin (rather than convex as in some

573 akidnognathids, or straight as in all others); anterior border of orbit located on anterior half of

574 skull; anvil-shaped epipterygoid processus ascendens with anterior tilt (see below); broad contact

575 between processus ascendens and parietal; dentary strongly bowed or boomerang-shaped; 
576 dentary ramus lateral groove/furrow weak (Ophidostoma) to absent. Some of these features have

577 been discussed elsewhere (Huttenlocker, 2009; Huttenlocker et al., 2011). Additional features of

578 the braincase shared by whaitsioids may be elucidated with further computed tomographic

579 research. The external morphology of the whaitsioid braincase also exhibits an anteriorly tilted

580 epipterygoid with an anterodorsally oriented leading edge of the processus ascendens (Figure 10)

581 as demonstrated by a specimen of the hofmeyriid Mirotenthes (SAM-PK- K11188) recovered

582 from coeval Cistecephalus AZ deposits at 'Good Luck' in association with Ophidostoma. This

583 contrasts with the more upright or posteriorly leaning epipterygoid of baurioids (e.g., Sigurdsen

584 et al., 2012:fig. 2) and other therocephalians (e.g., Huttenlocker et al., 2011:fig. 4). The

585 orientation of the processus ascendens has been incorporated as new character 136 in the present

586 phylogenetic analysis.

Evolution of early eutherocephalian dental morphology and surface texture-The

588

morphology and texture of the marginal dentition in therocephalians has only been discussed

589

anecdotally, but may provide important information regarding the interrelationships of

590

therocephalians, in addition to their diets (Huttenlocker et al., 2015). All eutherocephalians have

591 lost the serrations on the canines and antecanine teeth, but few eutherocephalians may have

592 retained smooth anterior and/or posterior carinae (e.g., chthonosaurids, some akidnognathids). In

593 some Permian eutherocephalians, the incisors and precanines may bear longitudinal fluting (e.g.,

594 basal akidnognathids, whaitsioids, and ictidosuchid-grade baurioids) or large, flat facets (derived

595 akidnognathids). Incisor fluting was suggested to be plesiomorphic for Eutherocephalia by

596 Hopson and Barghusen (1986), although the postcanine enamel texture was not discussed in any

597 detail. The condition of the incisors in Ophidostoma is unknown, but the presence of enamel

598 striae on the postcanines strongly suggests that striated postcanine enamel was also 
599 plesiomorphic for the postcanines of early Eutherocephalia and its subclades, given its shared

600 presence in Ophidostoma, Akidnognathus, and Ictidosuchus. Incidentally, enamel fluting has also

601 been reported in the marginal dentition of the enigmatic scylacosaurian Scylacosuchus from

602 Russia (Ivakhnenko, 2011). Contrary to the recent suggestion of Huttenlocker et al. (2015:fig. 6)

603 that basal akidnognathids and ictidosuchid-grade baurioids evolved postcanine striae

604 independently, the new evidence from Ophidostoma suggests that a single evolutionary origin is

605 more parsimonious, followed by multiple losses of enamel fluting/striae on the antecanine teeth

606 and postcanines in derived Akidnognathidae, Whaitsioidea, and Baurioidea.

607

608 Diversification of Therapsids during the End-Guadalupian Extinction

609 Non-marine vertebrate diversifications and extinctions are poorly understood during the

610 middle-to-late Permian transition. Particularly, whereas most workers recognize marked

611 extinctions of entire groups by the end of the Guadalupian (e.g., dinocephalians, lycosuchids,

612 scylacosaurids), there is little consensus as to whether the proliferation of late Permian therapsid

613 assemblages during Wuchiapingian times constitutes survival and opportunistic expansion of

614 ecospace by pre-existing lineages (long-fuse) or a rapid radiation of new lineages (short-fuse)

615 during the extinction's aftermath (Fröbisch, 2008, 2013; Lucas, 2017). For example, Lucas

616 (2017) most recently characterized the extinction of dinocephalian faunas as an abrupt "global

617 event" (p. 55), although systematic paleontological collecting in the middle Permian

618 Tapinocephalus and Pristerognathus AZs suggests the turnover was more complex, and that the

619 apparent severity of dinocephalian extinctions is exaggerated by oversplit dinocephalian

620 taxonomy and poor temporal resolution (Rubidge et al., 2013; Day et al., 2015a,b). Nevertheless,

621 others have identified shifts in overall extinction rates of some post-Guadalupian therapsid 
622 lineages - a potential driver of apparent (raw) diversity shifts in some Wuchiapingian lineages

623 (Brocklehurst et al., 2015) - while others still have raised doubts about the quality of the fossil

624 record and its ability to resolve the magnitude of turnover of middle-to-late Permian assemblages

625 (Fröbisch, 2008, 2013; Irmis et al., 2013).

626 We suggest that the apparent turnover of therocephalians can be characterized by a long-

627 fuse model in which classic late Permian clades (e.g., whaitsioids, baurioids) originated

628 concurrently with basal therocephalians of the middle Permian, but at lower abundances. This

629 hypothesis is supported by renewed collecting efforts in the Teekloof Formation by one of us

630 (RMHS), helping to further clarify therapsid ecological turnover during this time. Firstly, the

631 new record of Microwhaitsia represents one of the oldest known Gondwanan whaitsiids, as other

632 whaitsiid records from southern Africa are typically confined to the uppermost Cistecephalus

633 and lower Daptocephalus AZs (Huttenlocker and Abdala, 2015). Microwhaitsia firmly

634 establishes that whaitsiids already exhibited a Pangean-wide distribution by Tropidostoma AZ

635 times (early Wuchiapingian), an observation that is consistent with the record of the closely

636 allied Viatkosuchus from the Capitanian or Wuchiapingian-aged Kotelnich assemblage of Russia

637 (Golubev, 2000; Benton et al., 2012) (Fig. 11). Secondly, long-term collecting efforts by one of

638 us (RMHS) to elucidate the assemblages of the different members of the Teekloof Formation

639 have produced additional whaitsioid and baurioid records (see Tables 2 and 3). Some of these-

640 including a hofmeyriid (SAM-PK-K10525) (Fig. 12), an indeterminate ictidosuchid-grade

641 baurioid (SAM-PK-K6886) and a second baurioid with possible affinities to Ictidosuchoides

642 (SAM-PK-K11319) — were collected from the lower Poortjie Member or equivalent beds, which

643 contains a Pristerognathus AZ fauna that corresponds to either the latest Capitanian or earliest

644 Wuchiapingian global stages (Fig. 1). 

summarized elsewhere in the context of the Permo-Triassic mass extinction (Huttenlocker et al., 647 2011; Huttenlocker, 2013, 2014). For example, Huttenlocker (2014) failed to identify evidence 648 of diversification rate shifts in small-bodied therocephalian lineages near the Permo-Triassic 649 boundary, but noted a significant shift associated with the earlier divergence of the 650 Eutherocephalia clade. This was attributed to either increasing origination rates of 651 eutherocephalians or to sampling bias in the Tropidostoma and Cistecephalus AZs where 652 therocephalian fossils are more abundant (Smith et al., 2012). More recently, Brocklehurst et al. 653 (2015) showed that uneven origination and extinction rates (particularly elevated extinction) 654 could be a driver of diversification rate shifts in Permo-Triassic tetrapods. Notably, both 655 origination and extinction rates of therocephalians rose steadily into the late Permian (Fig. 11), 656 despite the long lineage durations sustained by a few representative taxa during the

657 Wuchiapingian (e.g., Ictidosuchoides, some hofmeyriids). In this sense, origination/extinction 658 rates indicate that therocephalians (particularly eutherocephalians) were, on the whole, resilient 659 to the effects of the extinction, although this was dependent upon high rates of turnover and 660 replacement by individual genera. Unlike some baurioid lineages, whaitsioids became wholly 661 extinct prior to the Permo-Triassic boundary as therocephalian origination rates began to 662 markedly decrease. The reasons for this differential extinction remain unclear, but have been 663 linked to differences in life history strategies evident in the two groups (Huttenlocker and Botha664 Brink, 2013, 2014; Botha et al., 2016). Consequently, future collecting of precious middle-to-late 665 Permian specimens will be crucial to further resolve the evolutionary dynamics of 666 therocephalians spanning the end-Guadalupian and Permo-Triassic mass extinctions. 667 
671 light on the early evolution of eutherocephalians during the middle-to-late Permian transition.

672 Phylogenetic analysis recovers both of the new taxa within Whaitsioidea, with Microwhaitsia as 673 an early whaitsiid and Ophidostoma as an aberrant whaitsioid outside the hofmeyriid+whaitsiid 674 clade. Consequently, Microwhaitsia represents the oldest whaitsiid from Gondwana and, along 675 with additional early hofmeyriid and baurioid records, underscores the early dichotomy between 676 whaitsiid-line and baurioid-line therocephalians. Moreover, the disjunct geographic occurrences 677 of Microwhaitsia and Viatkosuchus suggest that whaitsiids already exhibited a cosmopolitan 678 distribution by the early Wuchiapingian. During the end-Guadalupian, the extinction of basal 679 lycosuchids and scylacosaurids was offset by increasing origination/extinction rates of 680 eutherocephalians, which flourished into Wuchiapingian times. As a part of this radiation, 681 whaitsioids represent a previously underappreciated but successful clade of late Permian 682 eutherocephalians, but they did not survive the ecological impacts of the Permo-Triassic mass 683 extinction. Future collecting will provide added resolution on the middle-to-late Permian 684 transition, and will further clarify the dynamic replacement of basal therocephalians 685 (lycosuchids, scylacosaurids) by eutherocephalians and other early-diverging therapsid predators 686 (gorgonopsians, cynodonts). 
691 Town, and B. Rubidge and B. Zipfel of the Evolutionary Studies Institute (former Bernard Price

692 Institute, BP), Johannesburg. For comments on SAM-PK-K8516 and help in the field, we thank

693 S. Modesto. CT scans of SAM-PK-K8516 were produced by the University of Utah Core

694 Imaging Facility, Salt Lake City.

695

696

REFERENCES

697

698

Abdala, F. 2007. Redescription of Platycraniellus elegans (Therapsida, Cynodontia) from the

699 Lower Triassic of South Africa, and the cladistic relationships of eutheriodonts. Palaeontology 50:591-618.

701

702

703

Abdala, F., T. Jashashvili, B. S. Rubidge, and J. van den Heever. 2014. New material of Microgomphodon oligocynus (eutherapsida, therocephalia) and the taxonomy of southern african bauriidae, p. 209-231 in C. F. Kammerer, K. D. Angielczyk, and J. Fröbisch (eds.) Early Evolutionary History of the Synapsida. Springer, Dordrecht.

705

706

707

708
Abdala, F., C. F. Kammerer, M. O. Day, S. Jirah, and B. S. Rubidge. 2014. Adult morphology of the therocephalian Simorhinella baini from the middle Permian of South Africa and the taxonomy, paleobiogeography, and temporal distribution of the Lycosuchidae. Journal of Paleontology 88:1139-1153.

Abdala, F., B. S. Rubidge, and J. van den Heever. 2008. The oldest therocephalians (Therapsida, Eutheriodontia) and the early diversification of Therapsida. Palaeontology 51:1011-1024. 
711 Attridge, J. 1956. The morphology and relationships of a complete therocephalian skeleton from

712 the Cistecephalus Zone of South Africa. Proceedings of the Royal Society of Edinburgh.

713 Section B 66:59-93.

714 Benton, M. J., A. J. Newell, G. D. Price, and A. A. Kurkin. 2012. Preservation of exceptional

715 vertebrate assemblages in Middle Permian fluviolacustrine mudstones of Kotel'nich,

716 Russia: stratigraphy, sedimentology, and taphonomy. Palaeogeography,

717 Palaeoclimatology, Palaeoecology 319:58-83.

718 Botha, J., F. Abdala, and R. Smith. 2007. The oldest cynodont: new clues on the origin and early

719 diversification of Cynodontia. Zoological Journal of the Linnean Society 149:477-492.

720 Botha-Brink, J., D. Codron, A. K. Huttenlocker, K. D. Angielczyk, and M. Ruta. 2016. Breeding

721 young as a survival strategy during Earth's greatest mass extinction. Scientific Reports

$7226: 24053$.

723 Brink, A. S. 1956. On Aneugomphius ictidoceps Broom \& Robinson. Palaeontologia Africana $724 \quad 4: 97-115$.

725 Brink, A. S. 1980. On the genus Theriognathus Owen (including Whaitsia, Notosollasia,

726 Alopecopsis, Notaelurops, Moschorhynchus and Aneugomphius). Annals of the

727 Geological Survey of South Africa 14:1-37.

728 Brocklehurst, N., M. Ruta, J. Müller, and J. Fröbisch. 2015. Elevated extinction rates as a trigger

729 for diversification rate shifts: early amniotes as a case study. Scientific Reports 5:17104.

730 Broom, R. 1911. On some new South African Permian reptiles. Proceedings of the Zoological

$731 \quad$ Society of London 81:1073-1082.

732 Broom, R. 1935. On some new genera and species of Karroo fossil reptiles. Annals of the Transvaal Museum 18:55-72. 
734 Broom, R. 1948. A contribution to our knowledge of the vertebrates of the Karoo beds of South

735

736

737

738

739

740

741

742

743

744

745

746

747

748

749

750

751

752

753

754

755

756

Africa. Transactions of the Royal Society of Edinburgh 61:577-629.

Cole, D. I. 1992. Evolution and development of the Karoo Basin, Pp. 87-99 in M.J. De Wit \& I.G.D. Ransome (eds.), Inversion Tectonics of the Cape Fold Belt, Karoo and Cretaceous Basins of Southern Africa, A.A. Balkema, Rotterdam.

Crompton, A. W. 1955. A revision of the scaloposauridae with special reference to kinetism in this family. Navorsinge Van Die Nasionale Museum 1:149-183.

Day, M. O., S. Güven, F. Abdala, S. Jirah, B. Rubidge, and J. Almond. 2015a. Youngest dinocephalian fossils extend the Tapinocephalus Zone, Karoo Basin, South Africa. South African Journal of Science 111:1-5.

Day, M. O., J. Ramezani, S. A. Bowring, P. M. Sadler, D. H. Erwin, F. Abdala, and B. S. Rubidge. 2015b. When and how did the terrestrial mid-Permian mass extinction occur? Evidence from the tetrapod record of the Karoo Basin, South Africa. Proc. R. Soc. B 282(1811):20150834.

Fröbisch, J. 2008. Global taxonomic diversity of anomodonts (Tetrapoda, Therapsida) and the terrestrial rock record across the Permian-Triassic boundary. PLoS One 3(11):e3733.

Fröbisch, J. 2013. Vertebrate diversity across the end-Permian mass extinction-Separating biological and geological signals. Palaeogeography, Palaeoclimatology, Palaeoecology $372: 50-61$.

Golubev, V. K. 2000. The faunal assemblages of Permian terrestrial vertebrates from Eastern Europe. Paleontological Journal 34(suppl. 2):S211-S224.

Haughton, S. H. 1918. Some new carnivorous Therapsida, with notes upon the braincase in certain species. Annals of the South African Museum 12:175-216. 
757 Heever, J. A. van den. 1994. The cranial anatomy of the early Therocephalia (Amniota:

758 Therapsida). Annals of the University of Stellenbosch 1:1-59.

759 Hillenius, W. J. 1994. Turbinates in therapsids: evidence for Late Permian origins of mammalian 760 endothermy. Evolution 48:207-229.

761 Hopson, J. A., and H. R. Barghusen. 1986. An analysis of therapsid relationships. Pp. 83-106 in

762

763

764

765

766

767

768

769

770

771

772

773

774

775

776

777

N. Hotton, P. D. MacLean, J. J. Roth, and E. C. Roth (eds.) The Ecology and Biology of Mammal-like Reptiles. Smithsonian Institution Press, Washington.

Huttenlocker, A. K. 2009. An investigation into the cladistic relationships and monophyly of therocephalian therapsids (Amniota: Synapsida). Zoological Journal of the Linnean Society 157:865-891.

Huttenlocker, A. K. 2013. Paleobiology of therocephalian synapsids (Amniota) and the effects of the end-Permian extinction on size, growth and bone microstructure. Ph.D. dissertation, University of Washington, Seattle.

Huttenlocker, A. K. 2014. Body size reductions in nonmammalian eutheriodont therapsids (Synapsida) during the end-Permian mass extinction. PLoS One 9:e87553.

Huttenlocker, A. K. and F. Abdala. 2015. Revision of the first therocephalian, Theriognathus microps Owen (Therapsida: Whaitsiidae), and implications for cranial ontogeny and allometry in nonmammalian eutheriodonts. Journal of Paleontology 89:645-664.

Huttenlocker, A. K., and J. Botha-Brink. 2013. Body size and growth patterns in the therocephalian Moschorhinus kitchingi (Therapsida: Eutheriodontia) before and after the end-Permian extinction in South Africa. Paleobiology 39:253-277. 
778 Huttenlocker, A. K., and J. Botha-Brink. 2014. Bone microstructure and the evolution of growth

779 patterns in Permo-Triassic therocephalians (Amniota, Therapsida) of South Africa. PeerJ

$780 \quad 2: \mathrm{e} 325$.

781 Huttenlocker, A. K., and C. A. Sidor. 2012. Taxonomic revision of therocephalians (Therapsida:

782 Theriodontia) from the Lower Triassic of Antarctica. American Museum Novitates

$783 \quad 3738: 1-19$.

784 Huttenlocker, A. K., and C. A. Sidor. 2016. The first karenitid (Therapsida, Therocephalia) from the upper Permian of Gondwana and the biogeography of Permo-Triassic therocephalians. Journal of Vertebrate Paleontology 36:e1111897.

Huttenlocker, A. K., C. A. Sidor, and K. D. Angielczyk. 2015. A new eutherocephalian (Therapsida, Therocephalia) from the upper Permian Madumabisa Mudstone Formation (Luangwa Basin) of Zambia. Journal of Vertebrate Paleontology 35:e969400.

Huttenlocker, A. K., C. A. Sidor, and R. M. H. Smith. 2011. A new specimen of Promoschorhynchus (Therapsida: Therocephalia: Akidnognathidae) from the Lower Triassic of South Africa and its implications for theriodont survivorship across the Permo-Triassic boundary. Journal of Vertebrate Paleontology 31:405-421.

Irmis, R. B., J. H. Whiteside, and C. F. Kammerer. 2013. Non-biotic controls of observed diversity in the paleontologic record: An example from the Permo-Triassic Karoo Basin of South Africa. Palaeogeography, Palaeoclimatology, Palaeoecology 372:62-77.

Ivakhnenko, M. F. 2011. Permian and Triassic therocephals (Eutherapsida) of Eastern Europe. Paleontological Journal 45:981-1144.

Kemp, T. S. 1972a. Whaitsiid Therocephalia and the origin of cynodonts. Philosophical Transactions of the Royal Society of London: Series B 264:1-54. 
801 Kemp, T.S. 1972b. The jaw articulation and musculature of the whaitsiid Therocephalia; pp.

802 213-230 in K.A. Joysey \& T.S. Kemp (eds.), Studies in Vertebrate Evolution. Winchester

803 Press, New York, U.S.

804 Kemp, T. S. 2012. The origin and radiation of therapsids. pp. 2-28 in A. Chinsamy (ed.)

805 Forerunners of Mammals: Radiation, Histology, Biology. Indiana University Press,

$806 \quad$ Bloomington.

807 Lewis, P. O. 2001. A likelihood approach to estimating phylogeny from discrete morphological $808 \quad$ character data. Systematic Biology 50:913-925.

809 Liu, J., and F. Abdala. 2017. Therocephalian (Therapsida) and chroniosuchian (Reptiliomorpha)

810 from the Permo-Triassic transitional Guodikeng Formation of the Dalongkou Section,

811 Jimsar, Xinjiang, China. Vertebrata PalAsiatica 55:24-40.

812 Lucas, S. G. 2017. Permian tetrapod extinction events. Earth-Science Reviews 170:31-60.

813 Mendrez, C. H. 1974a. Etude du crane d'un jeune specimen de Moschorhinus kitchingi Broom, 1920

814 (?Tigrisuchus simus Owen, 1876), Therocephalia, Pristerosauria, Moschorhinidae d'Afrique

815 Australe (Remarques sur les Moschorhinidae et les Whaitsiidae). Annals of the South

816 African Museum 64:71-115. [In French.]

817 Owen, R. 1876. Descriptive and Illustrated Catalogue of the Fossil Reptilia of South Africa in 818 the Collection of the British Museum. Printed by order of the Trustees, London.

819 Ronquist, F., P. van der Mark, and J. P. Huelsenbeck. 2009. Bayesian phylogenetic analysis

820 using MrBayes: Pp. 210-266 in A. M. Vandamme, M. Salemi, and P. Lemey (eds.) The

821 Phylogenetic Handbook $2^{\text {nd }}$ Edition. Cambridge University Press, Cambridge.

822 Rosset, A., L. Spadola, and O. Ratib. 2004. OsiriX: An open-source software for navigating in 823 multidimensional DICOM images. J. Digit. Imaging 17. 
824 Rubidge, B. S., D. H. Erwin, J. Ramezani, S. A. Bowring, and W. J. de Klerk. 2013. High-

825 precision temporal calibration of late Permian vertebrate biostratigraphy: U-Pb zircon

826 constraints from the Karoo Supergroup, South Africa. Geology 41:363-366.

827 Sidor, C.A., D. A. Vilhena, K. D. Angielczyk, A. K. Huttenlocker, S. J. Nesbitt, B. R. Peecook,

828 J. S. Steyer, R. M. H. Smith and L. A. Tsuji. 2013. Provincialization of terrestrial faunas

829 following the end-Permian mass extinction. Proceedings of the National Academy of

830 Sciences 110:8129-8133.

831 Sigurdsen, T. 2006. New features of the snout and orbit of a therocephalian therapsid from South $832 \quad$ Africa. Acta Palaeontologica Polonica 51:63-75.

833 Sigurdsen, T., A. K. Huttenlocker, S. P. Modesto, T. B. Rowe, and R. Damiani. 2012.

834 Reassessment of the morphology and paleobiology of the therocephalian Tetracynodon

835 darti (Therapsida), and the phylogenetic relationships of Baurioidea. Journal of

$836 \quad$ Vertebrate Paleontology 32:1113-1134.

837 Smith, R. M. H. 1987. Morphology and depositional history of exhumed Permian point bars in

838 the southwestern Karoo, South Africa. Journal Sedimentary Petrology 57:19-29.

839 Smith, R. M. H. 1990. Alluvial paleosols and pedofacies sequences in the Permian Lower

840 Beaufort of the southwestern Karoo Basin, South Africa. Journal Sedimentary Petrology

$841 \quad 60: 258-276$

842 Smith, R. M. H. 1993. Vertebrate taphonomy of Late Permian floodplain deposits in the 843 southwestern Karoo Basin of South Africa. Palaios 8:45-67.

844 Smith, R.M. H., and J. Botha-Brink. 2011. Morphology and composition of bone-bearing

845 coprolites from the Late Permian Beaufort Group, Karoo Basin, South Africa.

846 Palaeogeography, Palaeoclimatology, Palaeoecology 312:40-53. 
847 Smith, R. M. H., B. Rubidge, and M. van der Walt. 2012. Therapsid biodiversity patterns and

848 paleoenvironments of the Karoo Basin, South Africa: pp. 30-62 in A. Chinsamy (ed.)

849 Forerunners of Mammals: Radiation, Histology, Biology. Indiana University Press, $850 \quad$ Bloomington.

851 Swofford, D. 1999. PAUP* Phylogenetic analysis using parsimony v. 4.0 beta 10. Sinauer 852 Associates, Sunderland, MA.

853 Tatarinov, L. P. 1963. A new Late Permian therocephalian. Paleontological Journal 4:76-94.

854 Tatarinov, L. P. 1974. Theriodonts of the USSR. Trudy Paleontologicheskogo Instituta, $855 \quad$ Akademii Nauk SSSR 143:1-240. [in Russian]

856 Tatarinov, L. P. 1995. Viatkosuchus sumini, a new Late Permian therocephalian from the Kirov 857 region. Paleontological Journal 29:111-128.

858 Turner, B. R. 1978. Sedimentary patterns of uranium mineralization in the Beaufort Group of the 859 southern Karoo (Gondwana) Basin, South Africa. In: A.D.Miall (Editor), Fluvial 860 Sedimentology, Canadian Association of Petroleum Geologists. Memoir 5:831-848.

861 Watson, D. M. S., and A. S. Romer. 1956. A classification of therapsid reptiles. Bulletin of the 862 Museum of Comparative Zoology, Harvard 111:37-89.

863

864

865

866

867

868

869

870 
872

873 FIGURE 1. Specimen provenance and stratigraphic context of Teekloof Formation whaitsioids. 874 1, Provenance of SAM-PK-K10990 and K10984, Badshoek farm (De Hoop 117), near Beaufort 875 West, Western Cape Province; 2, Provenance of SAM-PK- K8516, Good Luck farm, near 876 Fraserburg, Northern Cape Province. Bulleted numbers to right of stratigraphic column indicate 877 ages of vertebrate assemblage zones in millions of years (Ma) (from Rubidge et al., 2013).

878 Geologic map modified from Smith (1993). Abbreviations: CiAZ, Cistecephalus Assemblage 879 Zone; DaptoAZ, Daptocephalus Assemblage Zone; Fm, Formation; M, Member; PristAZ, 880 Pristerognathus Assemblage Zone; TapinoAZ, Tapinocephalus Assemblage Zone; TrAZ, 881 Tropidostoma Assemblage Zone. [full page width] 882

883 FIGURE 2. Holotypic skull of Microwhaitsia mendrezi gen. et sp. nov. (SAM-PK-K10990) in 884 dorsal (A), ventral (B), and right lateral (C) views. [full page width]

885

886 FIGURE 3. Interpretive line drawings of the holotypic skull of Microwhaitsia mendrezi gen. et 887 sp. nov. (SAM-PK-K10990) in dorsal (A), ventral (B), and right lateral (C) views.

888 Abbreviations: d, dentary; $\mathbf{C}$, upper canine; cr.ch, crista choanalis; f, frontal; f.l, lacrimal 889 foramen; I5, fifth upper incisor; j, jugal; l, lacrimal; m, maxilla; n, nasal; p, parietal; pal, 890 palatine; pC, upper precanine; PC5, fifth upper postcanine; po, postorbital; pm, premaxilla; prf, 891 prefrontal; pt, pterygoid; sa, surangular; sm, septomaxilla; sp, splenial. [full page width] 892 
893 FIGURE 4. Stereopair images of the palate of the holotypic skull of Microwhaitsia mendrezi 894 gen. et sp. nov. (SAM-PK-K10990) in left oblique ventral (A) and posteroventral (B) views. 895 Note the narrow contact between the left crista choanalis and vomer without sutural connection. 896 [two-thirds page width]

897

898 FIGURE 5. Referred specimen of Microwhaitsia mendrezi gen. et sp. nov. (SAM-PK-K10984) 899 in dorsal (A), ventral (B), and left lateral (C) views. [one column's width]

900

901 FIGURE 6. Interpretive line drawings of referred specimen of Microwhaitsia mendrezi gen. et 902 sp. nov. (SAM-PK-K10984) in dorsal (A), ventral (B), and left lateral (C) views. Abbreviations:

903 C, upper canine alveolus; cr.ch, crista choanalis; ect, ectopterygoid; f, frontal; j, jugal; l, 904 lacrimal; m, maxilla; m.pal.f, maxillo-palatine foramen; n, nasal; pal, palatine; PC5, fifth upper 905 postcanine alveolus; prf, prefrontal; pt, pterygoid; v, vomer; v.suborb, suborbital vacuity. [one 906 column's width]

907

908 FIGURE 7. Volumized HRXCT scans of the skull of Ophidostoma tatarinovi gen. et sp. nov. 909 (SAM-PK-K8516) in dorsal (A), ventral (B), left lateral (C), and frontal (D) views. [full page 910 width]

911

912 FIGURE 8. Interpretive line drawings of the skull of Ophidostoma tatarinovi gen. et sp. nov.

913 (SAM-PK-K8516) in dorsal (A), ventral (B), left lateral (C), and frontal (D) views.

914 Abbreviations: a, angular; d, dentary; ect, ectopterygoid; c, lower canine; $\mathbf{C}$, upper canine; f, 915 frontal; fen.m, mandibular fenestra; i, lower incisor; j, jugal; l, lacrimal; m, maxilla; n, nasal; p, 
916 parietal; part, prearticular; pbs, para-basisphenoid; PC6, sixth upper postcanine; po, postorbital;

917 pm, premaxilla; prf, prefrontal; pt, pterygoid; q-qj, quadrate-quadratojugal complex; sa,

918 surangular; sm, septomaxilla; sp, splenial; sq, squamosal; v.ipt, interpterygoid vacuity;

919 v.suborb, suborbital vacuity. [full page width]

920

921 FIGURE 9. Conservative phylogenetic relationships of the major clades of eutherocephalians, 922 showing conflicting arrangements obtained from Bayesian and parsimony analyses as polytomies

923 (tree length $=381$; consistency index $(\mathrm{CI})=0.438$; retention index $=0.789$; rescaled $\mathrm{CI}=0.346$ ).

924

925 FIGURE 10. New specimen of the hofmeyriid Mirotenthes digitipes Attridge, 1956 (SAM-PK926 K11188) from the upper Cistecephalus Assemblage Zone of 'Good Luck.' Specimen shown in 927 dorsal oblique view, showing the large temporal fenestra and broad, anvil-shaped epipterygoid 928 (ept) processus ascendens. [two-thirds page width]

929

930 FIGURE 11. Stratigraphically calibrated phylogeny of middle Permian through Triassic

931 therocephalians showing calibration points for minimum divergence dates of major clades (A).

932 Light gray lines represent hypothetical phylogenetic branching, whereas black bars represent

933 observed stratigraphic ranges (dashed ends indicate taxa having unknown upper or lower

934 ranges). Graph (B) shows peak levels of eutherocephalian origination/extinction by the

935 Wuchiapingian stage. Abbreviations: An, Antarctica; Ch, China; Chx, Changxingian; CiAZ,

936 Cistecephalus Assemblage Zone; DaptoAZ, Daptocephalus Assemblage Zone; Ind, Induan; Na,

937 Namibia; Olen, Olenekian; PristAZ, Pristerognathus Assemblage Zone; Roa, Roadian; Ru, 
938 Russia; SA, South Africa; TapinoAZ, Tapinocephalus Assemblage Zone; TrAZ, Tropidostoma

939 Assemblage Zone; Tz, Tanzania; Wor, Wordian; Za, Zambia. [full page]

940

941 FIGURE 12. Representative hofmeyriid from the late Capitanian or earliest Wuchiapingian of

942 the Karoo Basin, South Africa, compared to other known specimens of Hofmeyria. SAM-PK-

943 K10525 (A), Hofmeyriidae from the Pristerognathus Assemblage Zone of Lombardskraal,

944 Beaufort West district, Western Cape Province. Specimen shows short, high rostrum, prefrontal-

945 postorbital contact in orbit, anteriorly expanded epipterygoid, and conical, non-serrated/non-

946 carinated maxillary teeth. BP/1/4404 (BP, former Bernard Price Institute, now Evolutionary

947 Studies Institute, Johannesburg) (B), Hofmeyria cf. H. atavus from the Cistecephalus

948 Assemblage Zone of Matjiesfontein (Highlands), Victoria West district, Northern Cape Province.

949 BP/1/1399 (C), Hofmeyria cf. H. atavus from the Cistecephalus Assemblage Zone of

950 Driehoeksfontein, Murraysburg district, Western Cape Province. Numbers 14-136 are characters

951 listed in the phylogenetic analysis (see online Supplemental Appendix) followed by the derived

952 state in parentheses corresponding to hofmeyriids or other early whaitsioids. Abbreviations:

953 AZ, Assemblage Zone; PC, postcanine position \#. [full page]

954

955 TABLE 1. List of tetrapod fossils collected from the two farms 'Badshoek' and 'Good Luck' by 956 the Iziko South African Museum between 1996 and 2015. The newly described therocephalian

957 species are bold.

958

959 TABLE 2. African Permo-Triassic therocephalians by Karoo assemblage zone or equivalent

960 (updated from Abdala et al., 2008 and Huttenlocker, 2013). 
961

962 TABLE 3. Russian and Chinese Permo-Triassic therocephalians by assemblage zone or stage

963 (updated from Abdala et al., 2008, Ivakhnekno, 2011, and Huttenlocker, 2013).

964

965 


\section{Table $\mathbf{1}$ (on next page)}

Table 1

List of tetrapod fossils collected from the two farms 'Badshoek' and 'Good Luck' by the Iziko South African Museum between 1996 and 2015. The newly described therocephalian species are bold. 
1 Table 1. List of tetrapod fossils collected from the two farms 'Badshoek' and 'Good Luck' by

2 the Iziko South African Museum between 1996 and 2015. The newly described therocephalian 3 species are bold.

4

5

6

7

\section{(4)}

(2) 50
Specimen Number
Identification
Stratigraphic Level

\section{Good Luck (Matjiesfontein 412)}

SAM-PK-K11279 Dicynodon sp.

SAM-PK-K11189 Cistecephalus microrhinus

SAM-PK-K11188 Mirotenthes digitipes

SAM-PK-K8630 Pareiasaurus sp.

SAM-PK-K8508 Diictodon sp.

SAM-PK-K8509 Diictodon sp.

SAM-PK-K8513 Diictodon sp.

SAM-PK-K8303 Cistecephalus sp.

SAM-PK-K8304 Cistecephalus sp.

SAM-PK-K8510 Cistecephalus sp.

SAM-PK-K8512 Cistecephalus sp.

SAM-PK-K8629 Cistecephalus sp.

SAM-PK-K11187 Cistecephalus sp.

SAM-PK-K8307 Oudenodon sp.

SAM-PK-K11280 Oudenodon sp.

SAM-PK-K8507 Dicynodon sp.

SAM-PK-K8516 Ophidostoma tatarinovi (type)

SAM-PK-K8631 Eutherocephalia indet.

SAM-PK-K8511 Procynosuchus delaharpeae

SAM-PK-K11186 Procynosuchus delaharpeae

\section{Badshoek (De Hoop 117)}

SAM-PK-K10449 Pristerodon sp.

SAM-PK-K11008 Pristerodon sp.

SAM-PK-K11009 Pristerodon sp.

SAM-PK-K11010 Pristerodon sp.

SAM-PK-K11011 Diictodon sp.

SAM-PK-K10987 Pristerodon sp.

SAM-PK-K10985 Diictodon sp.

SAM-PK-K10986 Emydops sp.

SAM-PK-K11000 Tropidostoma sp.

SAM-PK-K10983 Gorgonopsia indet.

SAM-PK-K10984 Microwhaitsia mendrezi

SAM-PK-K10990

Microwhaitsia mendrezi (type)

CiAZ, Cistecephalus Assemblage Zone; DaptoAZ, Daptocephalus Assemblage Zone; TrAZ, Tropidostoma Assemblage Zone.
Steenkamp member (lower DaptoAZ)

Oukloof/Steenkamp (uppermost CiAZ)

Oukloof/Steenkamp (uppermost CiAZ)

Oukloof member (upper $\mathrm{CiAZ}$ )

Oukloof member (upper CiAZ)

Oukloof member (upper $\mathrm{CiAZ}$ )

Oukloof member (upper $\mathrm{CiAZ}$ )

Oukloof member (upper $C i \mathrm{AZ}$ )

Oukloof member (upper $\mathrm{CiAZ}$ )

Oukloof member (upper CiAZ)

Oukloof member (upper $\mathrm{CiAZ}$ )

Oukloof member (upper $\mathrm{CiAZ}$ )

Oukloof member (upper $\mathrm{CiAZ}$ )

Oukloof member (upper $\mathrm{CiAZ}$ )

Oukloof member (upper $\mathrm{CiAZ}$ )

Oukloof member (upper $\mathrm{CiAZ}$ )

Oukloof member (upper $\mathrm{CiAZ}$ )

Oukloof member (upper $\mathrm{CiAZ}$ )

Oukloof member (upper $\mathrm{CiAZ}$ )

Oukloof member (upper $\mathrm{CiAZ}$ )

Oukloof member (CiAZ)

Hoedemaker member (upper $\operatorname{Tr} \mathrm{AZ}$ )

Hoedemaker member (upper $\operatorname{TrAZ}$ )

Hoedemaker member (upper $\operatorname{TrAZ}$ )

Hoedemaker member (upper $\operatorname{Tr} \mathrm{AZ}$ )

Hoedemaker member (TrAZ)

Hoedemaker member $(\operatorname{Tr} \mathrm{AZ})$

Hoedemaker member (TrAZ)

Hoedemaker member (TrAZ)

Hoedemaker member (TrAZ)

Hoedemaker member (TrAZ)

Hoedemaker member (TrAZ) 


\section{Table 2 (on next page)}

Table 2

African Permo-Triassic therocephalians by Karoo assemblage zone or equivalent (updated from Abdala et al., 2008 and Huttenlocker, 2013). 
1 Table 2. African Permo-Triassic therocephalians by Karoo assemblage zone or equivalent 2 (updated from Abdala et al., 2008 and Huttenlocker, 2013).

3

4 Permian

5 Eodicynodon Assemblage Zone (Wordian) (2)

Glanosuchus macrops

Ictidosaurus angusticeps

Tapinocephalus Assemblage Zone (Capitanian) (8) Alopecodon priscus

Blattoidealestes gracilis*

Crapartinella croucheri*

Glanosuchus macrops

Ictidosaurus angusticeps

Lycosuchus vanderrieti

Pardosuchus whaitsi

Pristerognathus polyodon

Scylacosaurus sclateri

Simorhinella baini

Glanosuchus macrops

Hofmeyriidae (cf. Hofmeyria)

Ictidosuchidae (cf. Ictidosuchoides)

Lycosuchus vanderrieti

Pristerognathus polyodon

Tropidostoma Assemblage Zone (Wuchiapingian) (6)

Choerosaurus dejageri

Hofmeyria atavus

Ictidostoma hemburyi

Ictidosuchoides longiceps

Ictidosuchus primaevus

Microwhaitsia mendrezi

Cistecephalus Assemblage Zone (Wuchiapingian) (8)

Mupashi migrator

Euchambersia mirabilis

Hofmeyria atavus

Ichibengops munyamadziensis

Ictidostoma hemburyi

Ictidosuchoides longiceps

Mirotenthes digitipes

Ophidostoma tatarinovi

Polycynodon elegans

Theriognathus microps

Unnamed akidnognathid (USNM PAL 412421)

Akidnognathus parvus

Cerdosuchoides brevidens

Ictidochampsa platyceps

Ictidosuchoides longiceps

Ictidosuchops rubidgei

Lycideops longiceps

Pristerognathus Assemblage Zone (late Capitanian-Wuchiapingian) (5)

Daptocephalus Assemblage Zone (Wuchiapingian-Changxingian) (11) 


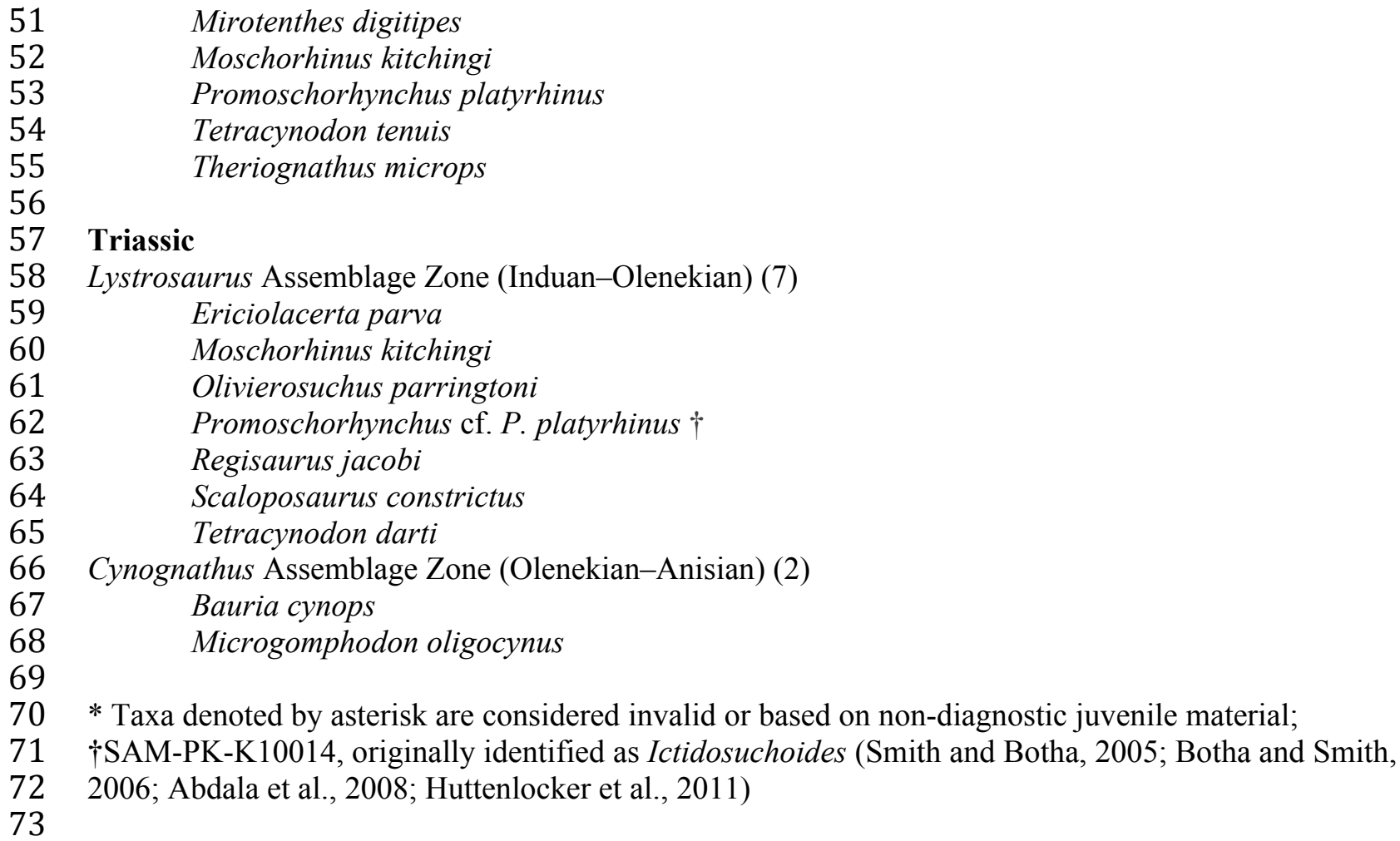

74

75 


\section{Table 3(on next page)}

Table 3

Russian and Chinese Permo-Triassic therocephalians by assemblage zone or stage (updated from Abdala et al., 2008, Ivakhnekno, 2011, and Huttenlocker, 2013). 
1 Table 3. Russian and Chinese Permo-Triassic therocephalians by assemblage zone or stage

2 (updated from Abdala et al., 2008, Ivakhnekno, 2011, and Huttenlocker, 2013).

3

4 Permian

5 Wordian-Capitanian (Ulemosaurus Assemblage Zone, Isheevo fauna or equivalent) (2)

6 Perplexisaurus(?) lepusculus*

$7 \quad$ Porosteognathus efremovi

8 late Capitanian-Wuchiapingian? (Deltavjatia Assemblage Zone, Kotelnich fauna or equivalent) (6)

Kotelcephalon viatkensis

Perplexisaurus (=Chlynovia) foveatus

Scalopodon tenuisfrons

Scalopodontes kotelnichi

Viatkosuchus sumini

Wuchiapingian (Proelginia Assemblage Zone, Ilynskoe fauna or equivalent) (1) Scylacosuchus orenburgensis

Wuchiapingian-Changxingian? (Scutosaurus Assemblage Zone, Sokolki fauna or equivalent) (2) Annatherapsidus petri Chthonosaurus velocidens

Changxingian (Archosaurus Assemblage Zone, Vyazniki fauna or equivalent) (6)

Dalongkoua fuae $\dagger$

Hexacynodon purlinensis*

Malasaurus germanus*

Moschowhaitsia vjuschkovi

Purlovia maxima

Whaitsiidae indet.

\section{Triassic}

Induan-Olenekian (Vetlugian stage or equivalent) (5)

Hazhenia concava

Scalopognathus multituberculatus*

Silphedosuchus orenburgensis

Urumchia lii

Yikezhaogia megafenestrala

Anisian (Eryosuchus Assemblage Zone, Donguzian fauna or equivalent) (7)

Antecosuchus ochevi

Dongusaurus schepetovi $\uparrow$

Nothogomphodon danilovi

Nothogomphodon sanjiaoensis

Ordosiodon lincheyuensis

Ordosiodon youngi

Traversodontoides wangwuensis

* Taxa denoted by asterisk are considered invalid or based on non-diagnostic material

$\uparrow$ Precise age uncertain. Regarded as Permo-Triassic by Liu and Abdala, 2017. 


\section{Figure 1}

Specimen provenance and stratigraphic context of Teekloof Formation whaitsioids.

1, Provenance of SAM-PK-K10990 and K10984, Badshoek farm (De Hoop 117), near Beaufort West, Western Cape Province; 2, Provenance of SAM-PK- K8516, Good Luck farm, near Fraserburg, Northern Cape Province. Bulleted numbers to right of stratigraphic column indicate ages of vertebrate assemblage zones in millions of years (Ma) (from Rubidge et al., 2013). Geologic map modified from Smith (1993). Abbreviations: CiAZ, Cistecephalus Assemblage Zone; DaptoAZ, Daptocephalus Assemblage Zone; Fm, Formation; M, Member; PristAZ, Pristerognathus Assemblage Zone; TapinoAZ, Tapinocephalus Assemblage Zone; TrAZ, Tropidostoma Assemblage Zone. 


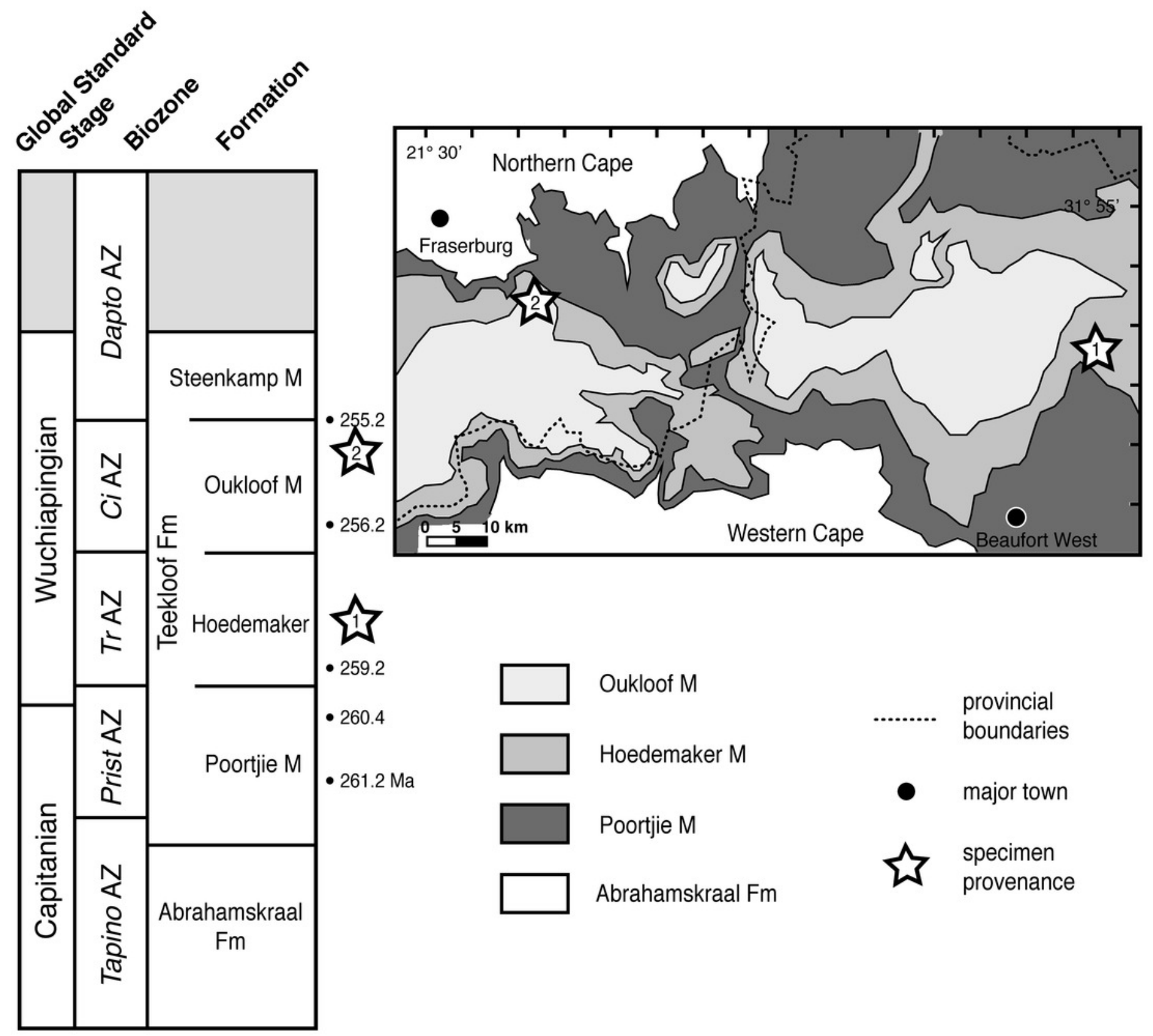




\section{Figure 2}

Holotypic skull of Microwhaitsia mendrezi gen. et sp. nov. (SAM-PK-K10990) in dorsal $(A)$, ventral $(B)$, and right lateral $(C)$ views.

A
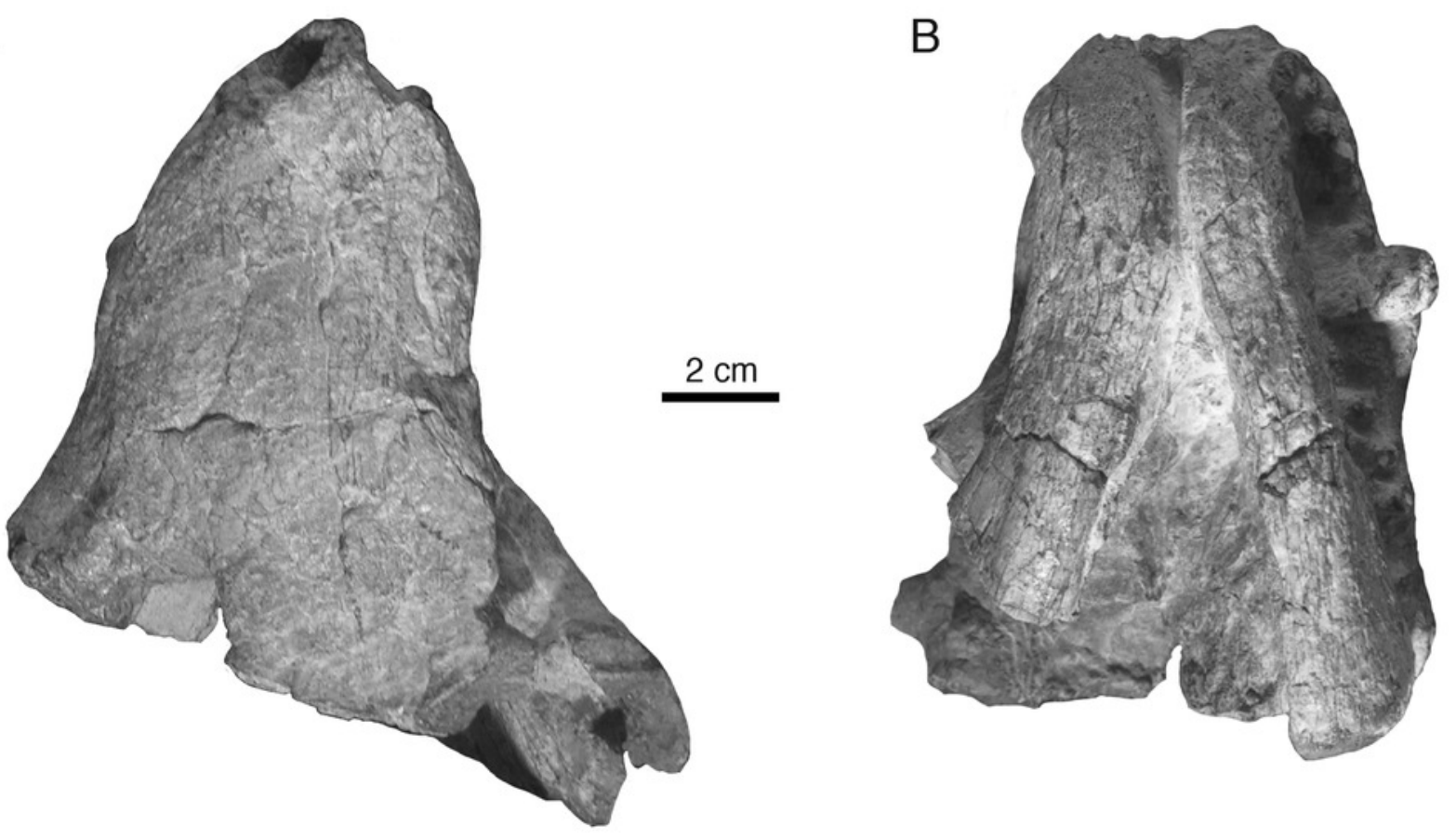

C

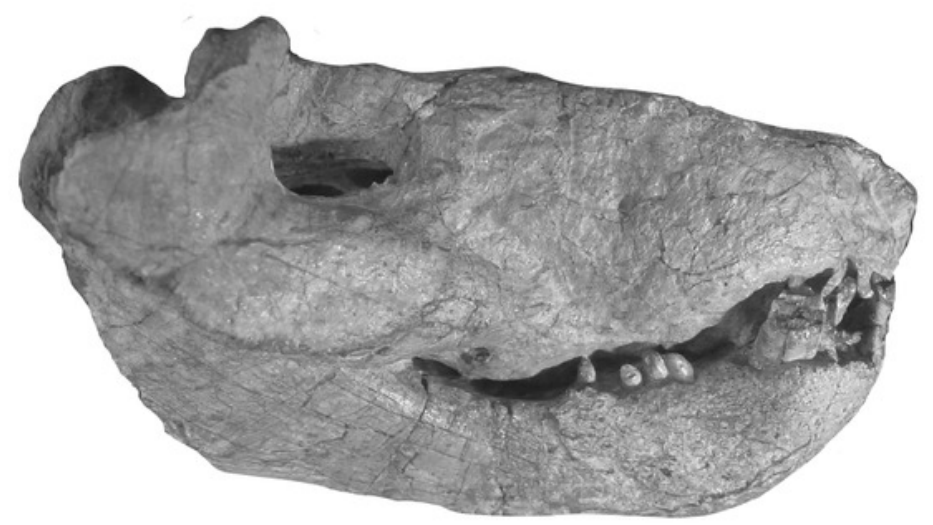


Figure 3

Interpretive line drawings of the holotypic skull of Microwhaitsia mendrezi gen. et sp. nov. (SAM-PK-K10990) in dorsal (A), ventral (B), and right lateral (C) views.

Abbreviations: d, dentary; C, upper canine; cr.ch, crista choanalis; f, frontal; f.I, lacrimal foramen; I5, fifth upper incisor; j, jugal; I, lacrimal; m, maxilla; n, nasal; p, parietal; pal, palatine; pC, upper precanine; PC5, fifth upper postcanine; po, postorbital; pm, premaxilla; prf, prefrontal; pt, pterygoid; sa, surangular; sm, septomaxilla; sp, splenial.

A

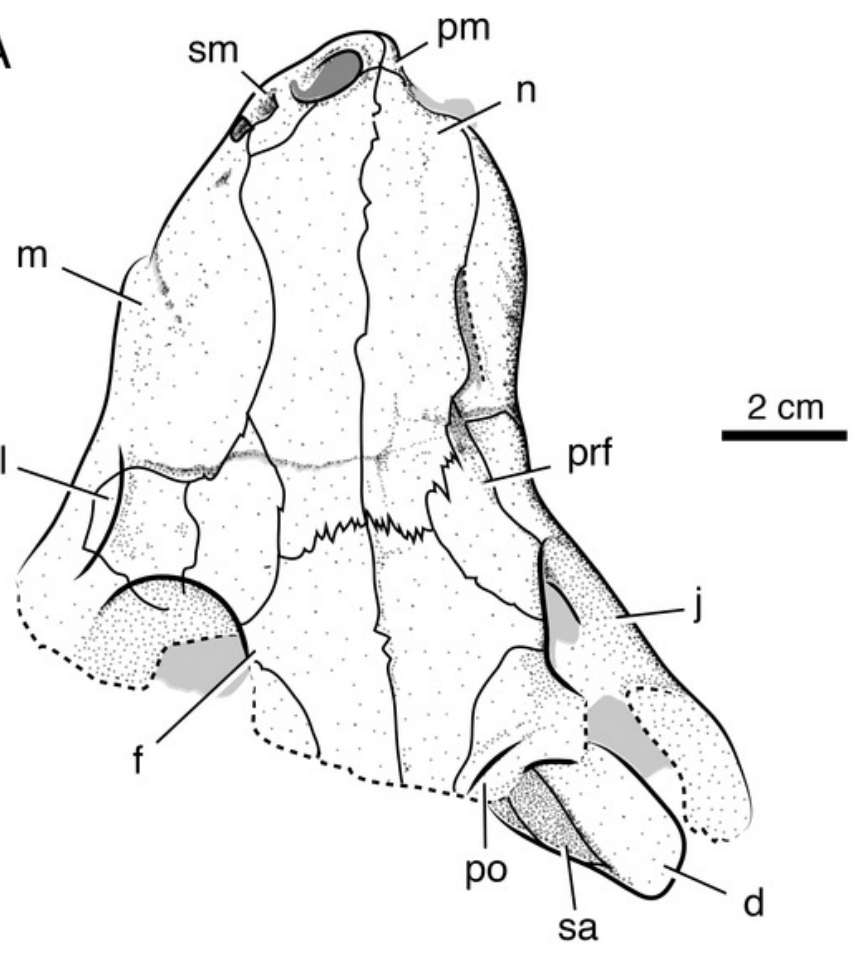

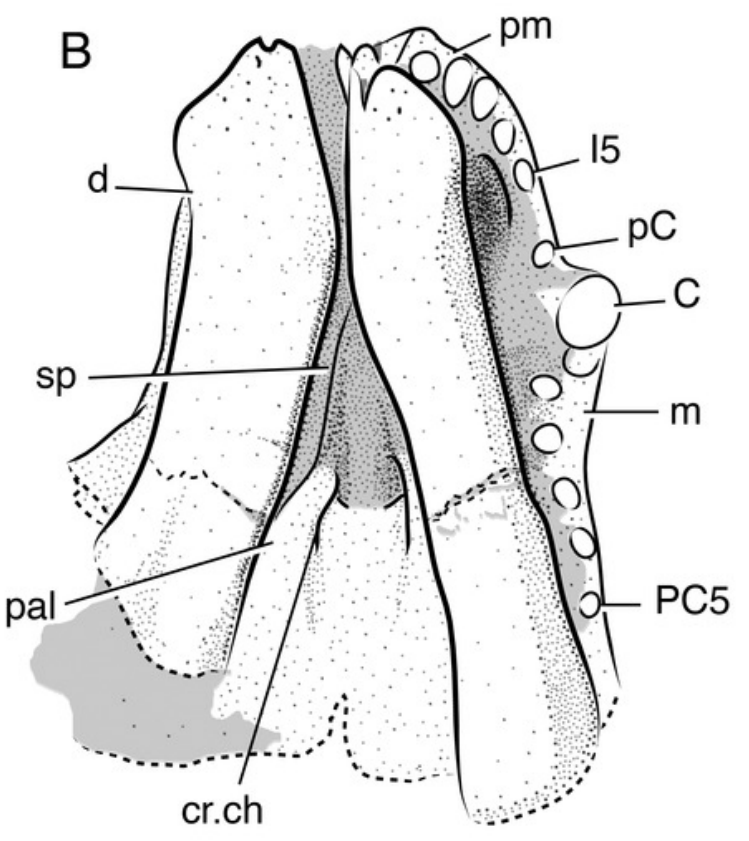

C

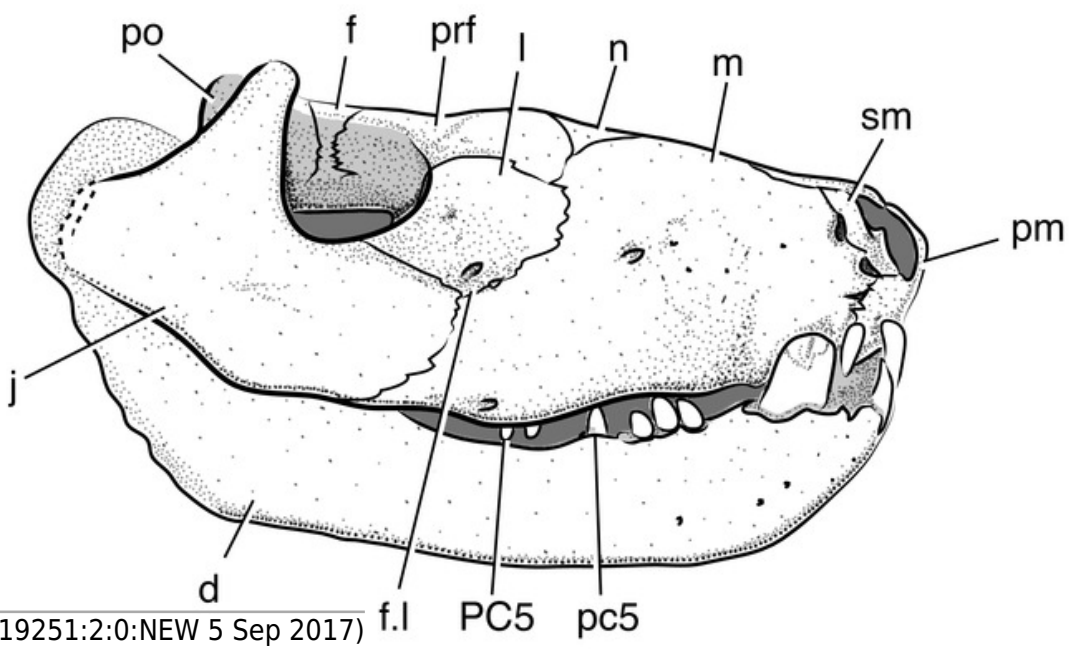




\section{Figure 4}

Stereopair images of the palate of the holotypic skull of Microwhaitsia mendrezi gen. et sp. nov. (SAM-PK-K10990) in left oblique ventral (A) and posteroventral (B) views.

Note the narrow contact between the left crista choanalis and vomer without sutural connection 

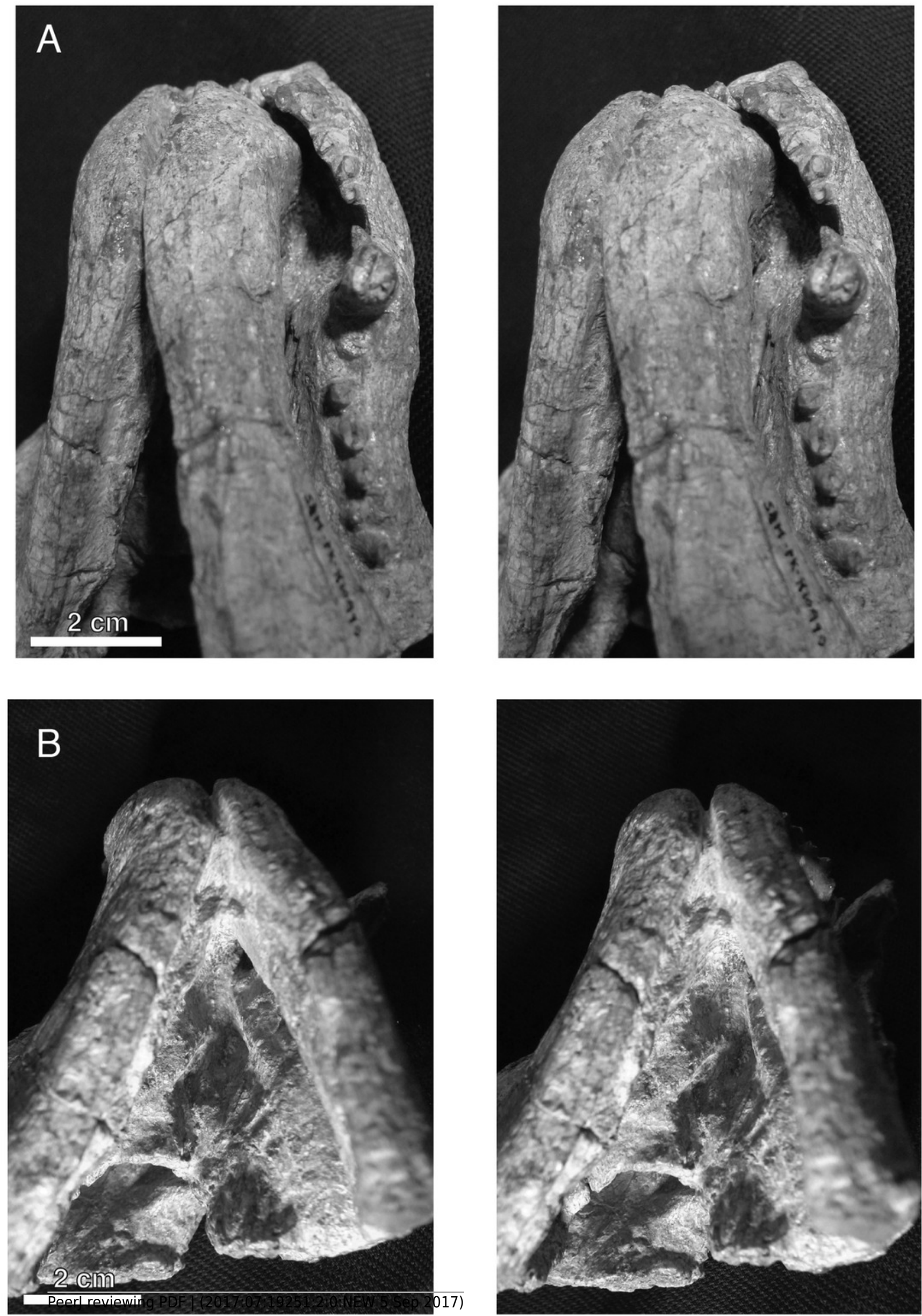
Figure 5

Referred specimen of Microwhaitsia mendrezi gen. et sp. nov. (SAM-PK-K10984) in dorsal $(A)$, ventral $(B)$, and left lateral $(C)$ views. 


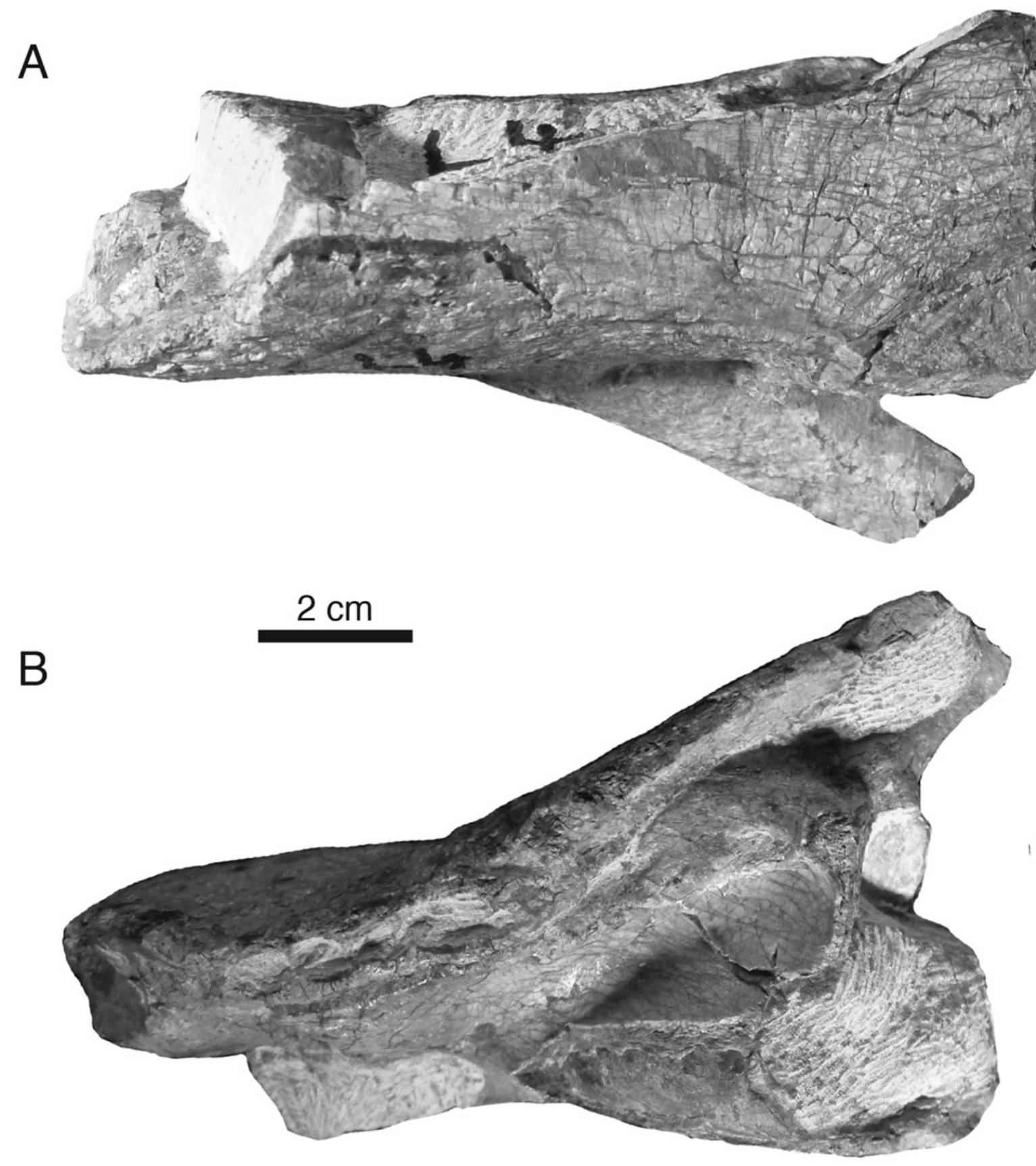

C

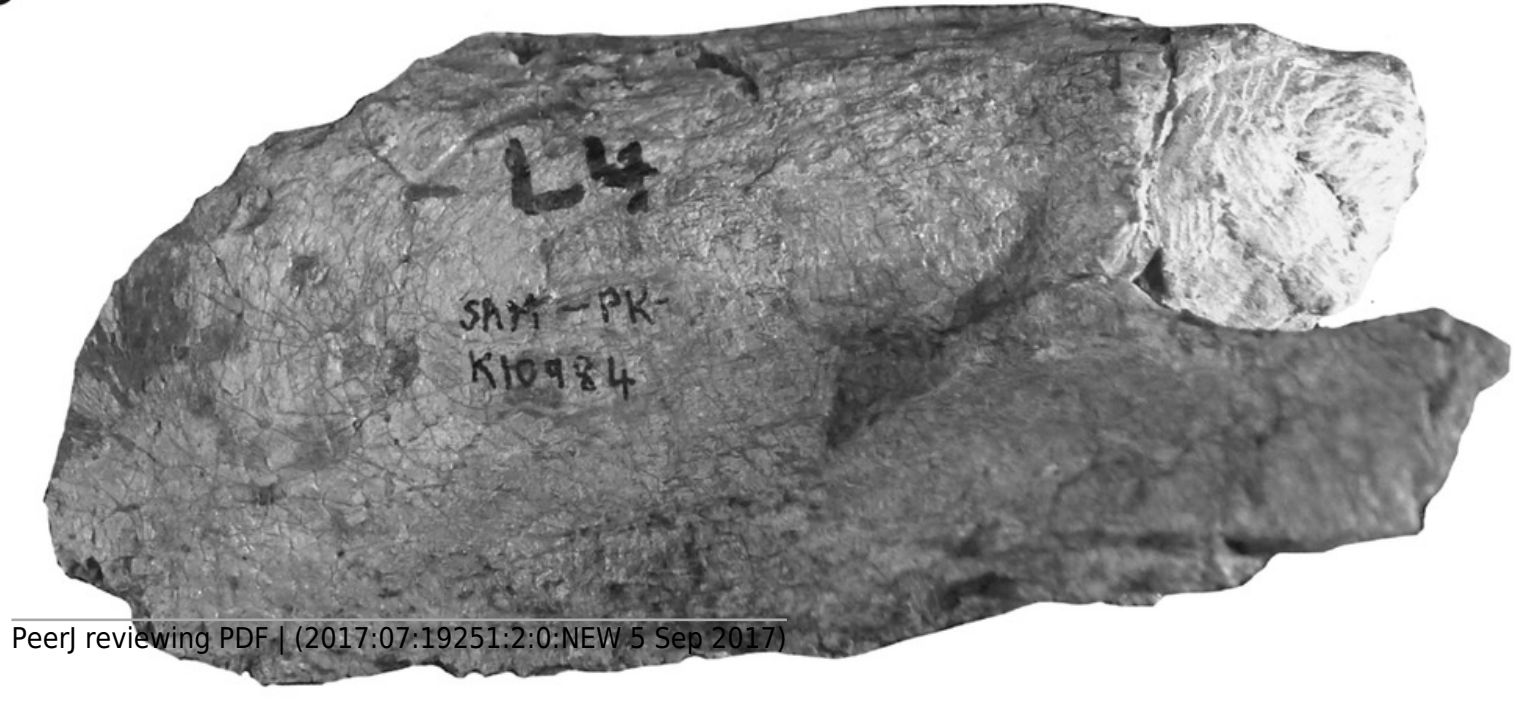




\section{Figure 6}

Interpretive line drawings of referred specimen of Microwhaitsia mendrezi gen. et sp. nov. (SAM-PK-K10984) in dorsal (A), ventral (B), and left lateral (C) views.

Abbreviations: C, upper canine alveolus; cr.ch, crista choanalis; ect, ectopterygoid; f, frontal; j, jugal; I, lacrimal; m, maxilla; m.pal.f, maxillo-palatine foramen; $\mathbf{n}$, nasal; pal, palatine; PC5, fifth upper postcanine alveolus; prf, prefrontal; pt, pterygoid; v, vomer; v.suborb, suborbital vacuity. 


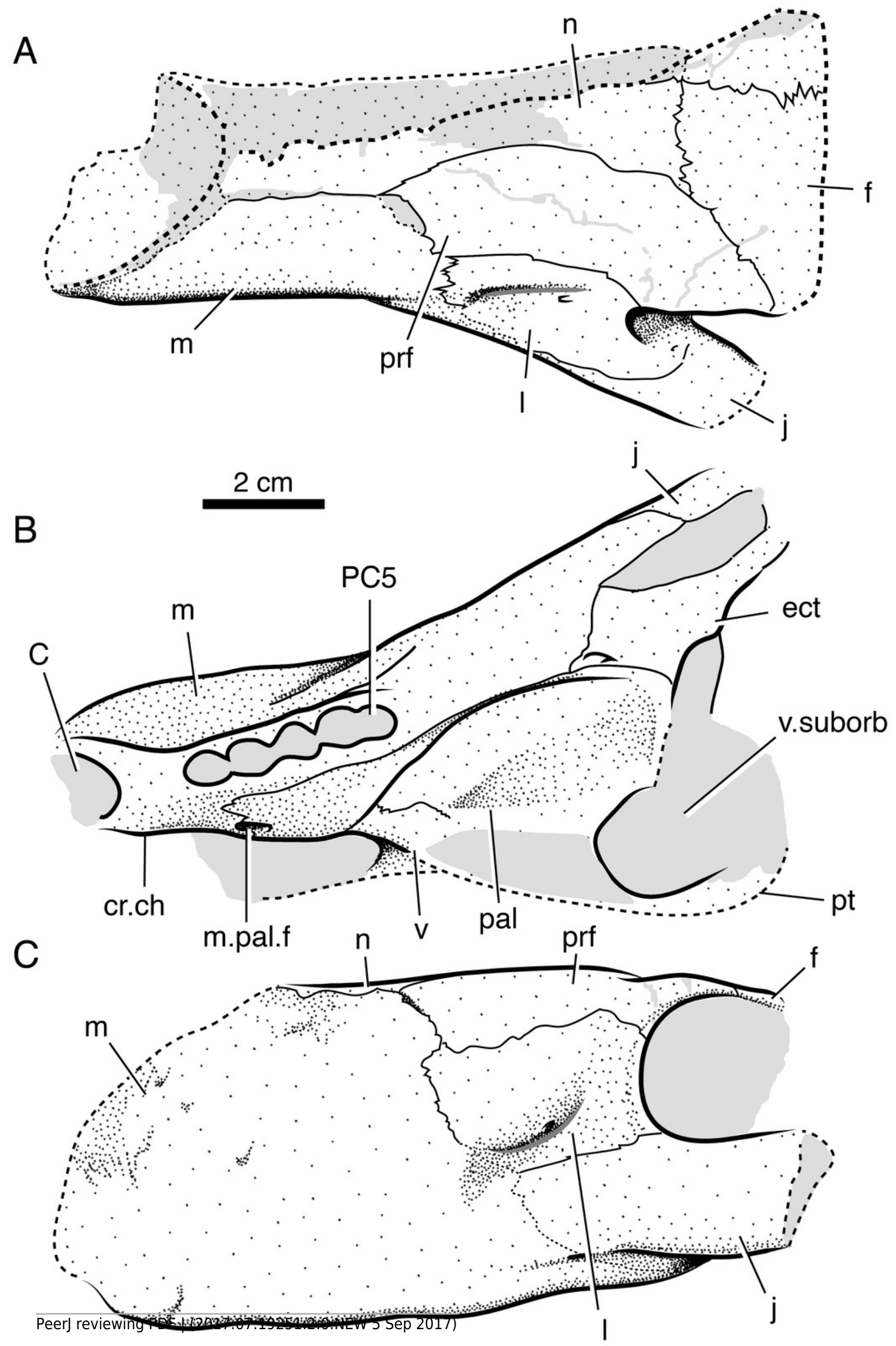


Figure 7

Volumized HRXCT scans of the skull of Ophidostoma tatarinovi gen. et sp. nov. (SAM-PKK8516) in dorsal (A), ventral (B), left lateral (C), and frontal (D) views.

A

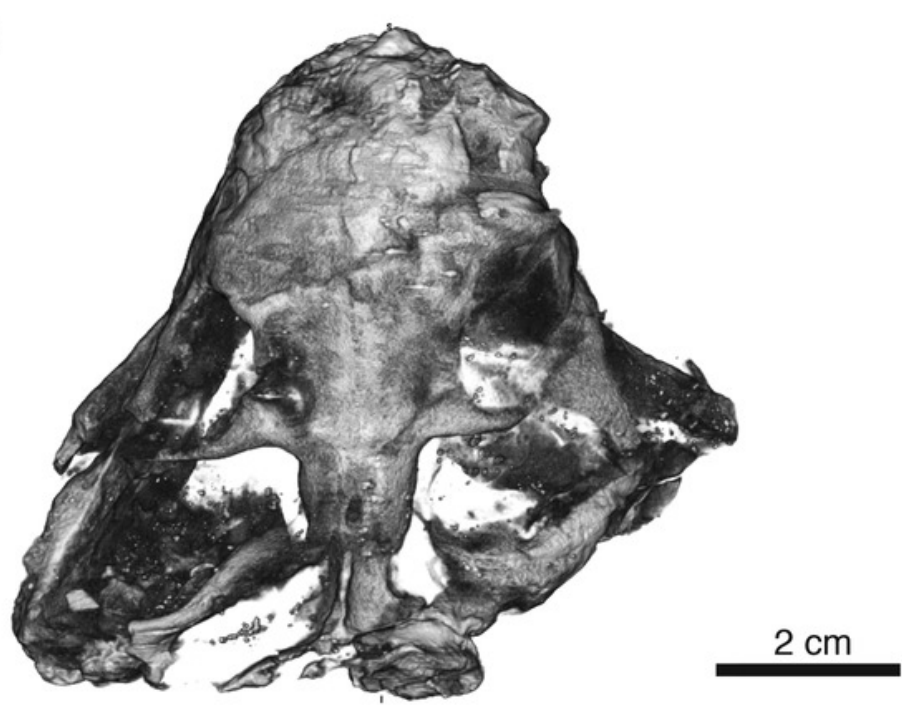

C

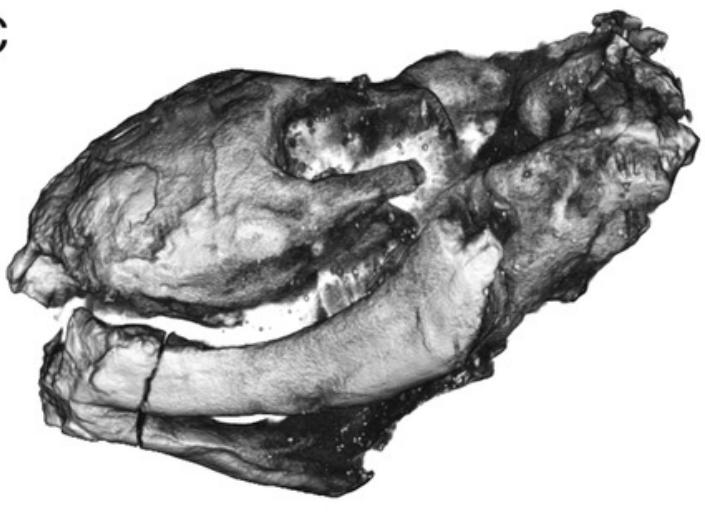

B

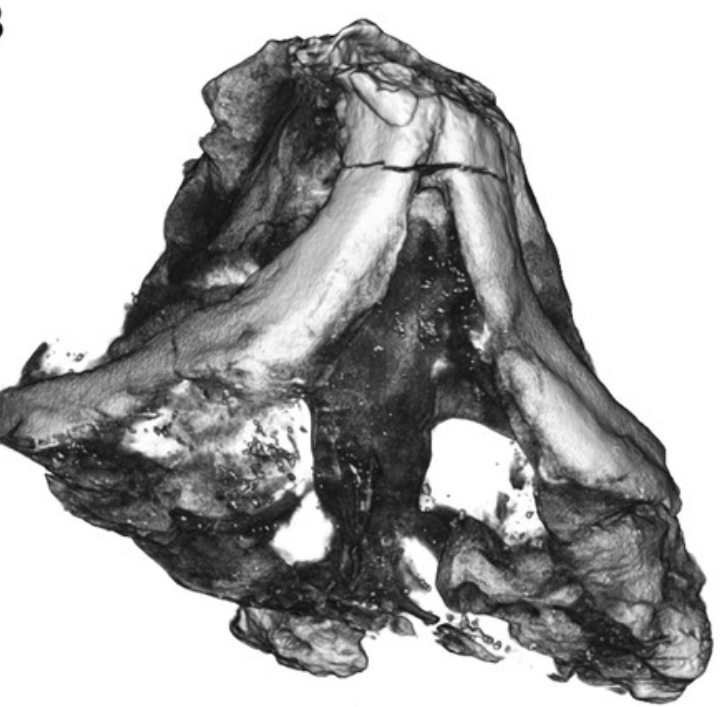

D

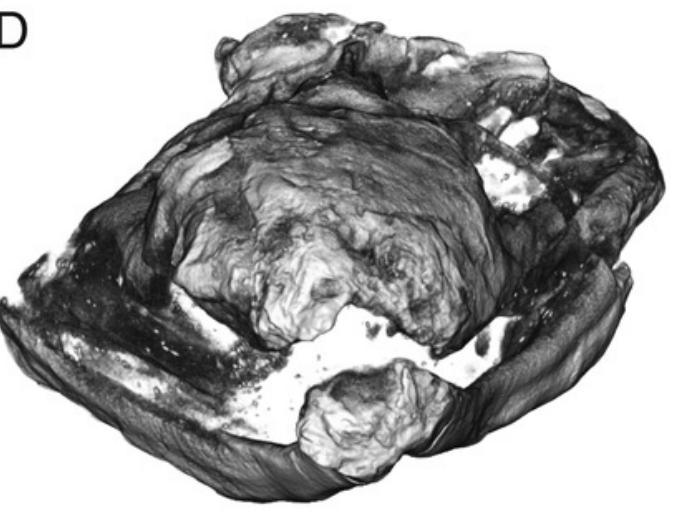




\section{Figure 8}

Interpretive line drawings of the skull of Ophidostoma tatarinovi gen. et sp. nov. (SAMPK-K8516) in dorsal (A), ventral (B), left lateral (C), and frontal (D) views.

Abbreviations: a, angular; d, dentary; ect, ectopterygoid; c, lower canine; C, upper canine; f, frontal; fen.m, mandibular fenestra; i, lower incisor; j, jugal; I, lacrimal; m, maxilla; $\mathbf{n}$, nasal; p, parietal; part, prearticular; pbs, para-basisphenoid; PC6, sixth upper postcanine; po, postorbital; pm, premaxilla; prf, prefrontal; pt, pterygoid; q-qj, quadrate-quadratojugal complex; sa, surangular; sm, septomaxilla; sp, splenial; sq, squamosal; v.ipt, interpterygoid vacuity; v.suborb, suborbital vacuity.

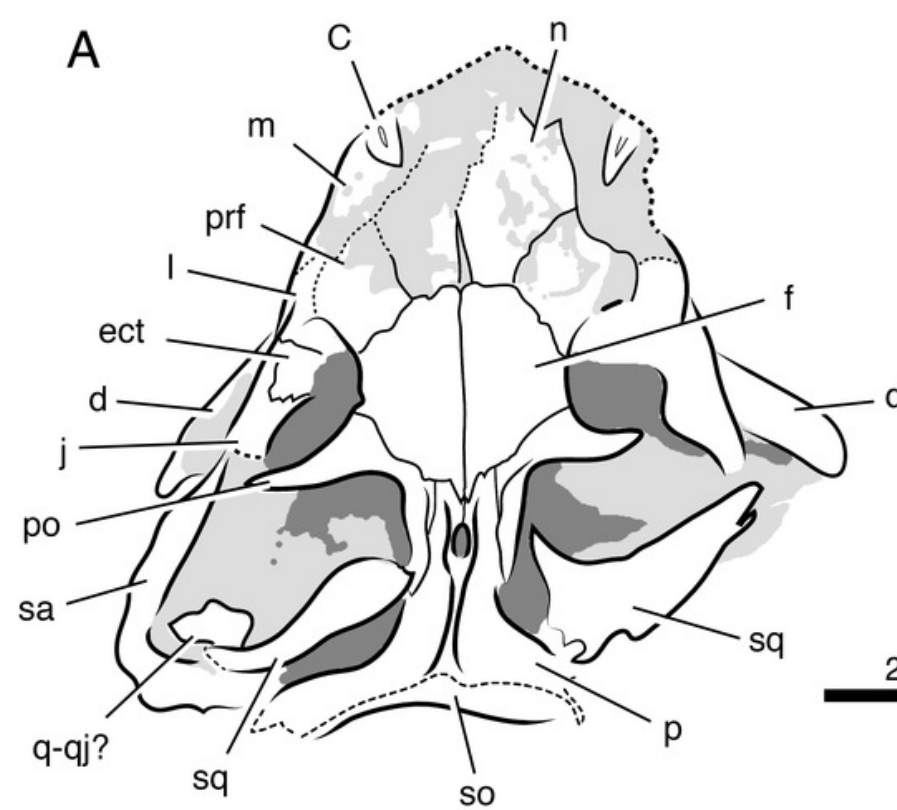

$2 \mathrm{~cm}$
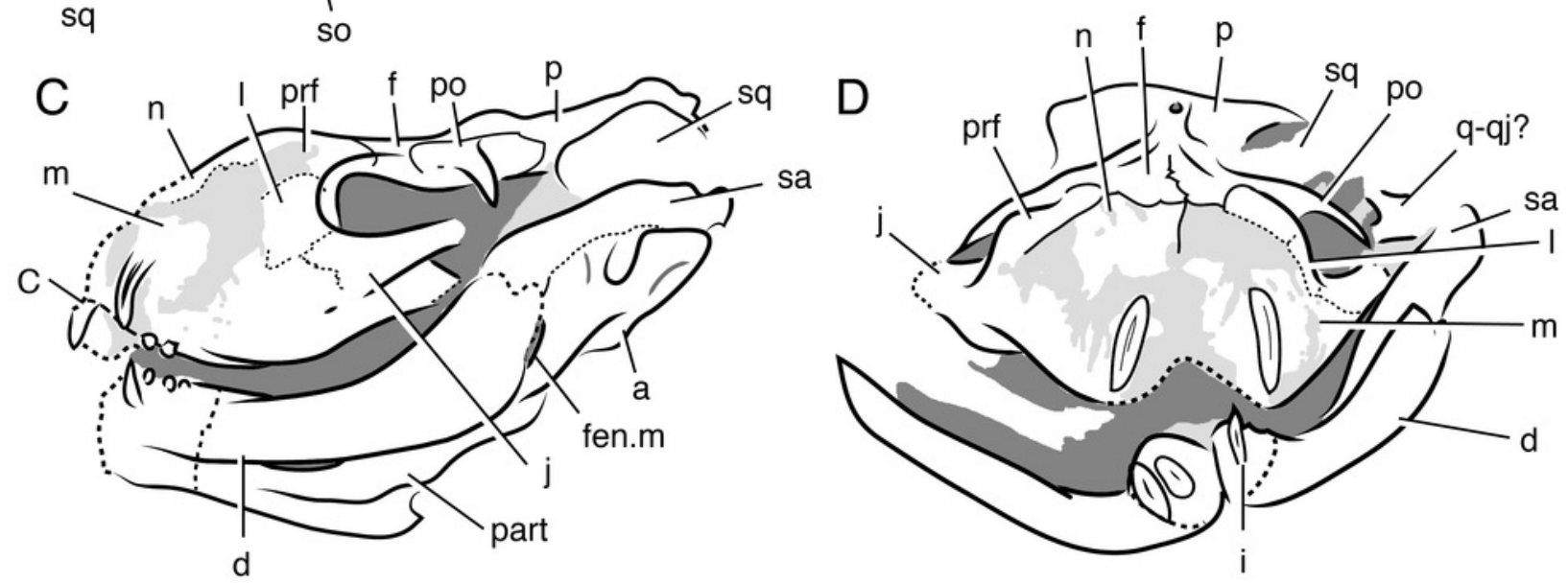


\section{Figure 9}

Conservative phylogenetic relationships of the major clades of eutherocephalians, showing conflicting arrangements obtained from Bayesian and parsimony analyses as polytomies (tree length $=381$; consistency index $(\mathrm{Cl})=0.438$; retention index $=0.789$; res

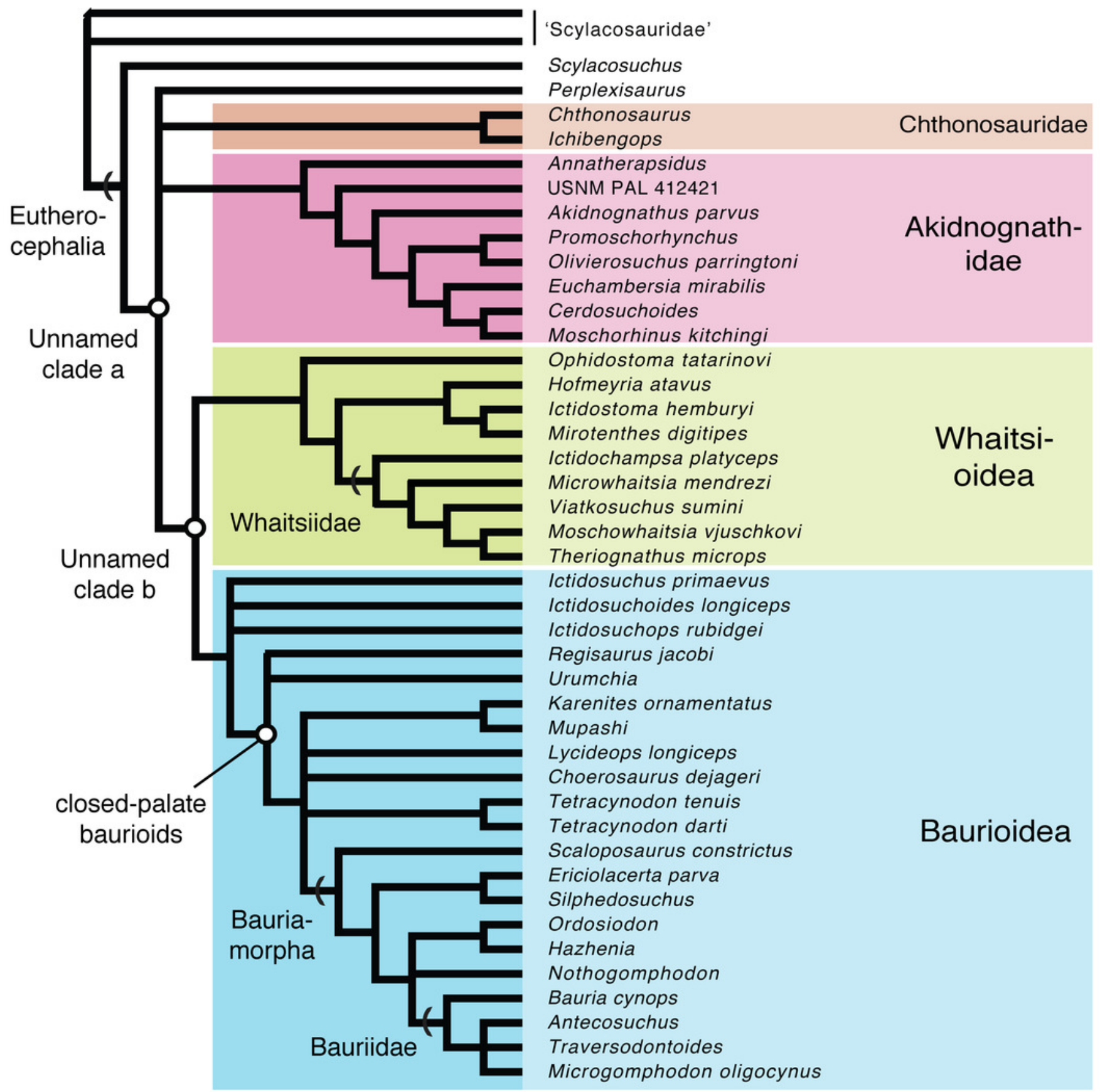




\section{Figure 10}

New specimen of the hofmeyriid Mirotenthes digitipes Attridge, 1956 (SAM-PKK11188) from the upper Cistecephalus Assemblage Zone of 'Good Luck.'

Specimen shown in dorsal oblique view, showing the large temporal fenestra and broad, anvil-shaped epipterygoid (ept) processus ascendens.

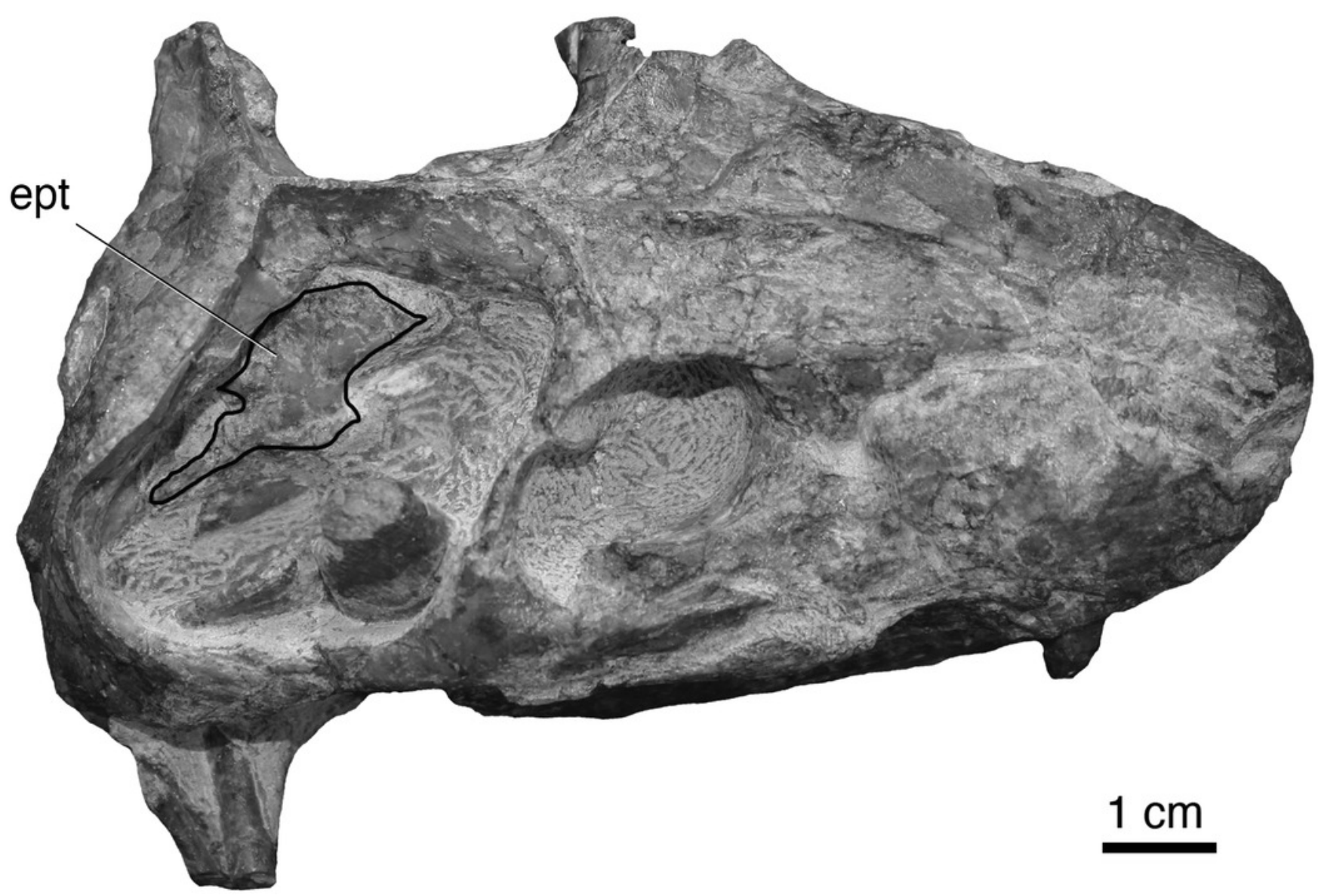




\section{Figure 11}

Stratigraphically calibrated phylogeny of middle Permian through Triassic therocephalians showing calibration points for minimum divergence dates of major clades (A).

Light gray lines represent hypothetical phylogenetic branching, whereas black bars represent observed stratigraphic ranges (dashed ends indicate taxa having unknown upper or lower ranges). Graph (B) shows peak levels of eutherocephalian origination/extinction by the Wuchiapingian stage. Abbreviations: An, Antarctica; Ch, China; Chx, Changxingian; CiAZ, Cistecephalus Assemblage Zone; DaptoAZ, Daptocephalus Assemblage Zone; Ind, Induan; Na, Namibia; Olen, Olenekian; PristAZ, Pristerognathus Assemblage Zone; Roa, Roadian; Ru, Russia; SA, South Africa; TapinoAZ, Tapinocephalus Assemblage Zone; TrAZ, Tropidostoma Assemblage Zone; Tz, Tanzania; Wor, Wordian; Za, Zambia. 


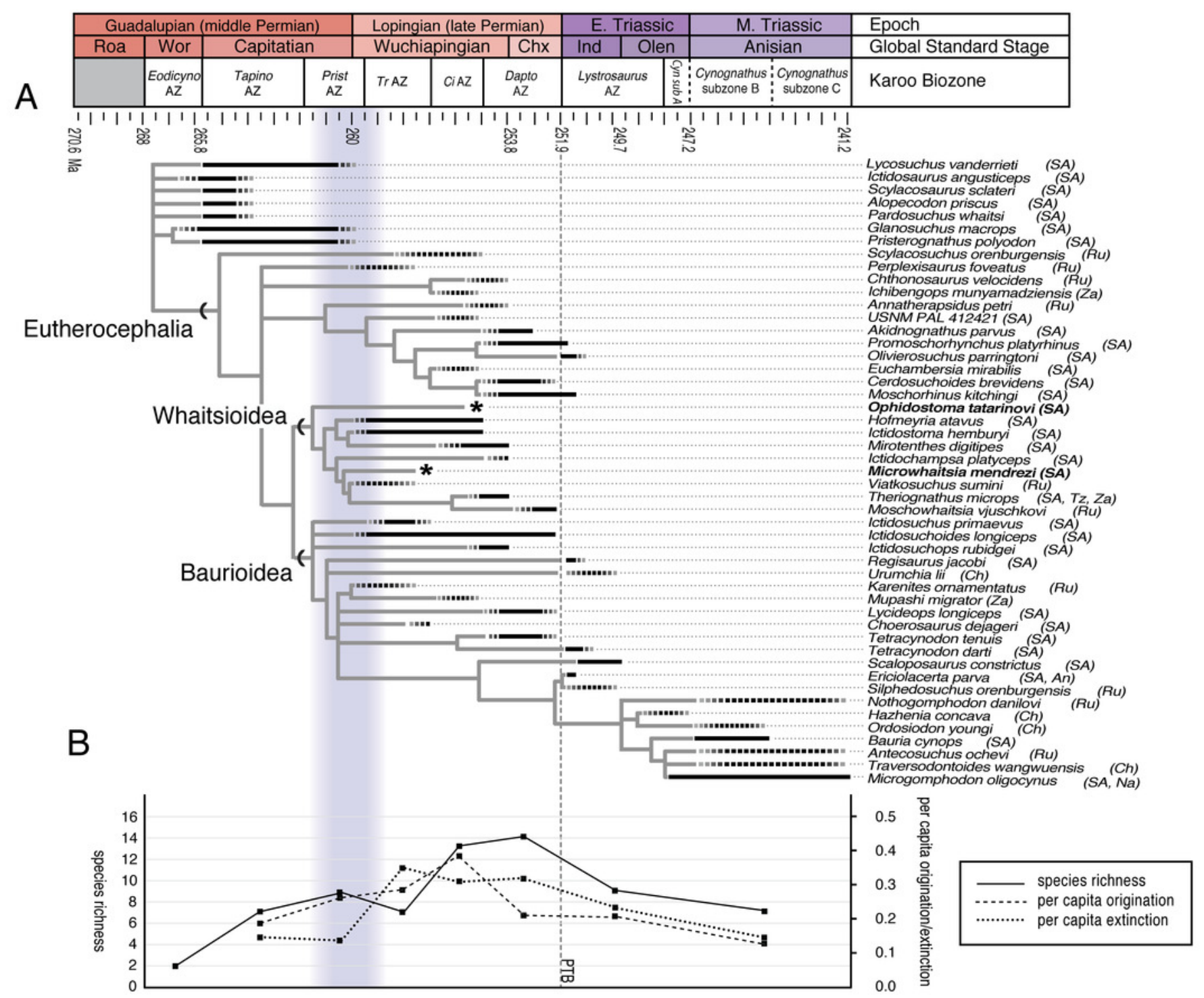




\section{Figure 12}

Representative hofmeyriid from the late Capitanian or earliest Wuchiapingian of the Karoo Basin, South Africa, compared to other known specimens of Hofmeyria.

SAM-PK-K10525 (A), Hofmeyriidae from the Pristerognathus Assemblage Zone of Lombardskraal, Beaufort West district, Western Cape Province. Specimen shows short, high rostrum, prefrontal-postorbital contact in orbit, anteriorly expanded epipterygoid, and conical, non-serrated/non-carinated maxillary teeth. BP/1/4404 (BP, former Bernard Price Institute, now Evolutionary Studies Institute, Johannesburg) (B), Hofmeyria cf. H. atavus from the Cistecephalus Assemblage Zone of Matjiesfontein (Highlands), Victoria West district, Northern Cape Province. BP/1/1399 (C), Hofmeyria cf. H. atavus from the Cistecephalus Assemblage Zone of Driehoeksfontein, Murraysburg district, Western Cape Province. Numbers 14-136 are characters listed in the phylogenetic analysis (see online Supplemental Appendix) followed by the derived state in parentheses corresponding to hofmeyriids or other early whaitsioids. Abbreviations: AZ, Assemblage Zone; PC, postcanine position \#. 


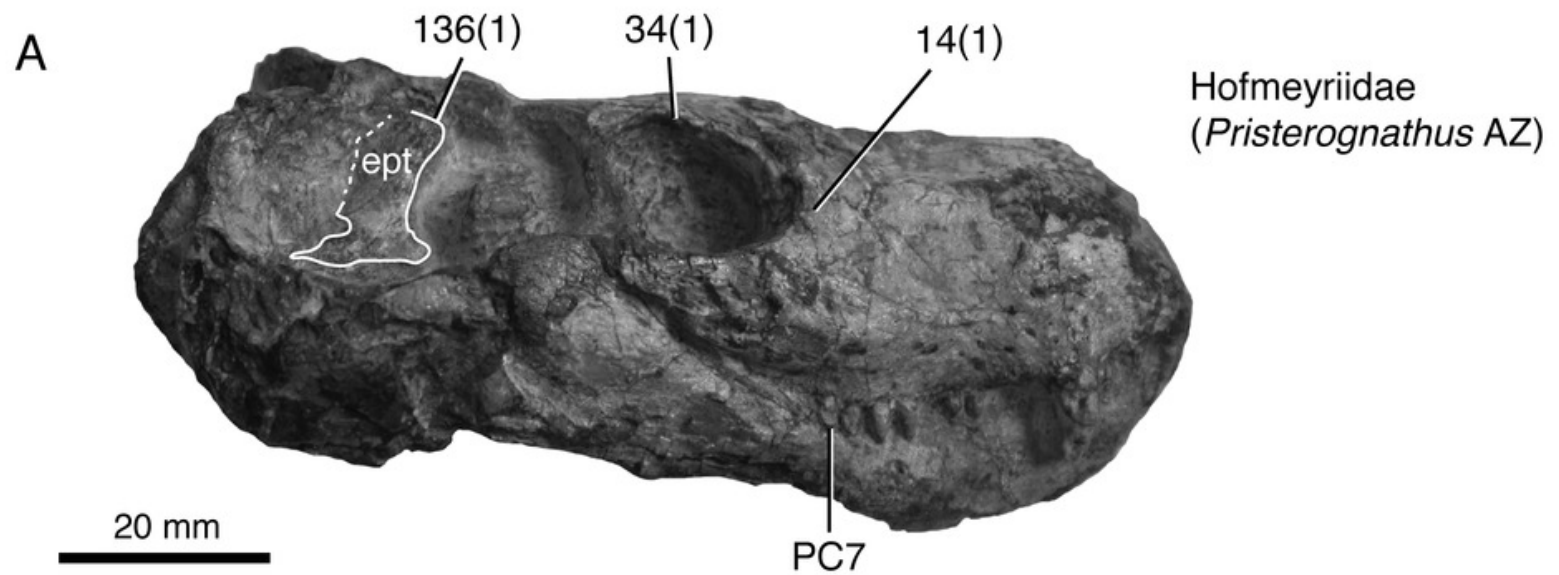

B Hofmeyria cf. H. atavus

(Cistecephalus AZ)

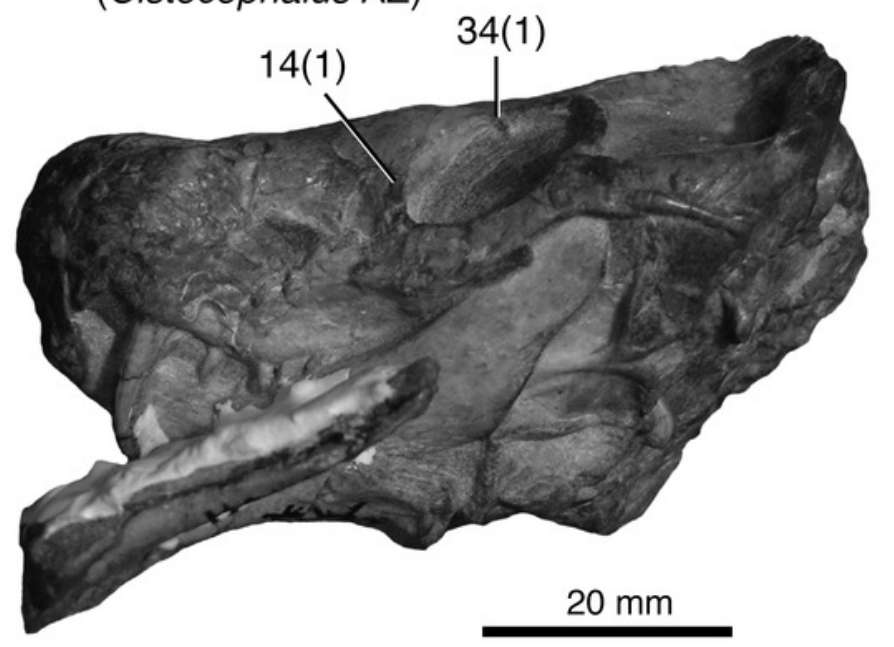

C

Hofmeyria cf. $H$. atavus (Cistecephalus AZ)

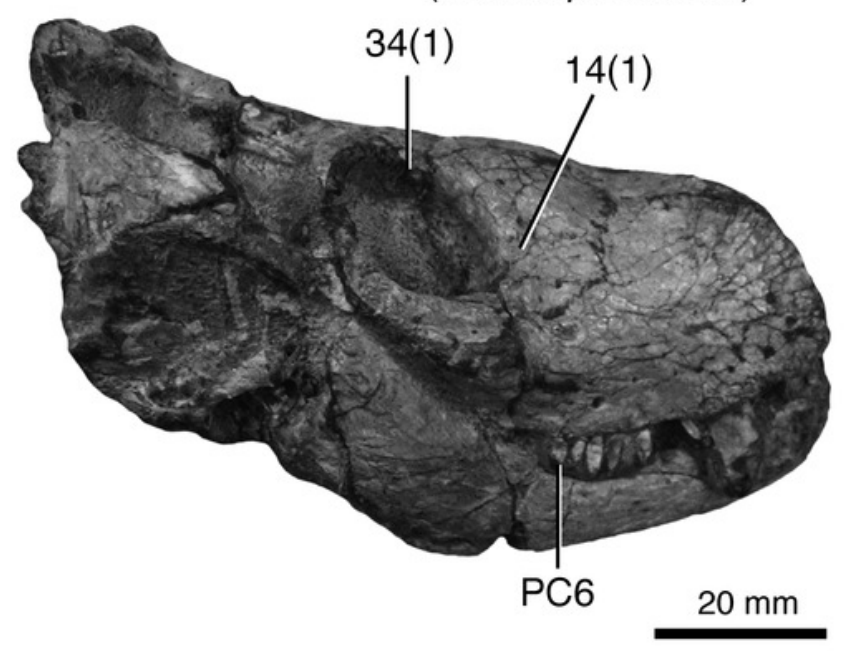

